\title{
Kv7 channels are upregulated during striatal neuron development and promote maturation of human iPSC-derived neurons
}

\author{
Vsevolod Telezhkin 1,2,3 (D) Marco Straccia ${ }^{4,5}$ - Polina Yarova ${ }^{2}$ • Monica Pardo ${ }^{4,5}$ - Sun Yung ${ }^{2}$. Ngoc-Nga Vinh ${ }^{2}$. \\ Jane M. Hancock ${ }^{6}$. Gerardo Garcia-Diaz Barriga ${ }^{4,5}$ - David A. Brown ${ }^{3}$. Anne E. Rosser ${ }^{2,7}$. Jonathan T. Brown ${ }^{8}$. \\ Josep M. Canals ${ }^{4,5}$ - Andrew D. Randall ${ }^{6,8}$ - Nicholas D. Allen ${ }^{2}$ Paul J. Kemp ${ }^{2}$
}

Received: 2 May 2018 / Revised: 14 May 2018 / Accepted: 15 May 2018 / Published online: 24 May 2018

(C) The Author(s) 2018

\begin{abstract}
Kv7 channels determine the resting membrane potential of neurons and regulate their excitability. Even though dysfunction of Kv7 channels has been linked to several debilitating childhood neuronal disorders, the ontogeny of the constituent genes, which encode $\mathrm{Kv} 7$ channels $(K N C Q)$, and expression of their subunits have been largely unexplored. Here, we show that developmentally regulated expression of specific $K C N Q$ mRNA and $\mathrm{Kv} 7$ channel subunits in mouse and human striatum is crucial to the functional maturation of mouse striatal neurons and human-induced pluripotent stem cell-derived neurons. This demonstrates their pivotal role in normal development and maturation, the knowledge of which can now be harnessed to synchronise and accelerate neuronal differentiation of stem cell-derived neurons, enhancing their utility for disease modelling and drug discovery.
\end{abstract}

Keywords $K C N Q \cdot \mathrm{Kv} 7 \cdot$ Human-induced pluripotent stem cells $\cdot$ Striatum $\cdot$ Patch-clamp

\section{Introduction}

Kv7 channels [4] are sub-threshold, voltage-gated potassium ion channels that are widely expressed in mammalian central and peripheral neurons [5]. They were first described in sympathetic neurons [4] and have subsequently been identified in a variety of neurons including medium spiny neurons (MSNs) of the striatum [33], sensory nociceptive structures [6, 27], hippocampal CA1 pyramidal cells [14, 31, 32], as well as in the substantia nigra [34]. Neuronal Kv7 channels are assembled of two Kv7.2 and two Kv7.3 subunits, most commonly, but not invariably $[18,40]$. Functionally, they help to maintain

Vsevolod Telezhkin

vsevolod.telezhkin@newcastle.ac.uk

1 School of Dental Sciences, Newcastle University, Framlington Place, Newcastle upon Tyne NE2 4BW, UK

2 School of Biosciences, Cardiff University, The Sir Martin Evans Building, Museum Avenue, Cardiff CF10 3AX, UK

3 Department of Neuroscience, Physiology and Pharmacology, London University College, London, UK

4 Department of Cell Biology, Immunology and Neuroscience, Faculty of Medicine, August Pi Sunyer Biomedical Research Institute (IDIBAPS), University of Barcelona, Barcelona, Spain and stabilise the neuronal resting membrane potential (Vm), thereby controlling neuronal excitability and action potential threshold [11]. In mammals, Kv7 channels, and/or their constituent subunits, are developmentally upregulated during early post-natal life [13,38,41], with associated changes in Vm [23] and excitability [30]. Kv7 channels have also been reported to play roles in survival, maturation and synapse development in embryonic stem cell-derived and human-induced pluripotent stem cell (hiPSC)-derived neurons [35, 44]. Being a critical determinant of neuronal excitability, regulated expression of Kv7 channels during neuronal differentiation and maturation ought logically to be vital for the progressive

5 Centro de Investigación Biomédica en Red sobre Enfermedades Neurodegenerativas (CIBERNED), Barcelona, Spain

6 School of Physiology and Pharmacology, University of Bristol, Bristol, UK

7 Institute of Psychological Medicine and Clinical Neurosciences, School of Medicine, Cardiff University, Hadyn Ellis Building, Cardiff CF24 4HQ, UK

8 Hatherly Laboratory, Institute of Biomedical and Clinical Sciences, University of Exeter Medical School, Exeter, UK 
hyperpolarization of $\mathrm{Vm}$ and its stabilisation below the threshold for voltage-gated $\mathrm{Na}^{+}$channel activation/inactivation [5], during early development. However, the importance of Kv7 channels in pre-natal neuronal development and maturation remains largely unexplored. In the present experiments, we have considered how far the developmental expression of Kv7 channels might contribute to the functional maturation of striatal neurons. Within the striatum, mature MSNs play an important role in the control of movement and in a range of cognitive and behavioural functions [7, 12] and show prominent degeneration in Huntington's disease (HD) [39]. They display conspicuous Kv7 currents which contribute to their $\mathrm{Vm}$ and action potential threshold to regulate their excitable behaviour $[8,33]$.

Thus, the present study was designed to test firstly the hypothesis that the functional neuronal development of mouse embryonic striatal neurons, isolated at embryonic day (E)13, E15 and E17 and cultured in vitro for up to 16 days, is associated with enhanced expression and activity of Kv7 channels. Once this was established in mouse striatum, the ontogenies of Kv7 subunits were determined in developing and adult striatum of the human brain. We then investigated the functional and molecular expression of $\mathrm{Kv} 7$ channels during neuronal differentiation and maturation of hiPSC-derived neurons. Finally, the idea that forced co-expression of Kv7.2 and Kv7.3 might represent a novel method by which to accelerate the functional maturation of neurons in vitro was tested using two independent hiPSC lines. Taken together, these data show that progressive expression of Kv7 channels during development of striatal neurons leads to hyperpolarization and increased excitability in vivo and that forced expression of Kv7 channels results in enhanced functional maturation of stem cell-derived neurons in vitro.

\section{Methods}

\section{Isolation and culture of embryonic mouse striatal neurons}

Striata were dissected from mouse embryos at stages E13, E15 and E17 and placed into hibernate medium (Invitrogen Life Technologies, Paisley, Strathclyde, UK), gently triturated using a P1000 pipette and then centrifuged at $1000 \mathrm{rpm}$ for $2 \mathrm{~min}$. The resultant tissue pellets were resuspended in 1$3 \mathrm{~mL}$ of accutase (PAA Laboratories GmbH Yeovil, Somerset, UK) with $200 \mathrm{U} / \mathrm{mL}$ DNase1 (Sigma-Aldrich, Poole, Dorset, UK) and incubated at $37^{\circ} \mathrm{C}$ with regular gentle trituration, for 10-30 $\mathrm{min}$, before the addition of equal volumes of Advanced DMEM/F12 medium (Invitrogen Life Technologies), and final mechanical disaggregation. The cell suspensions were centrifuged at $110 \mathrm{~g}$ for $5 \mathrm{~min}$ and the pelleted cells were resuspended in $2-3 \mathrm{~mL}$ differentiation medium with the following composition: Advanced DMEM/ F12 (Invitrogen Life Technologies) adjusted to $1.8 \mathrm{mM} \mathrm{CaCl}_{2}$ (Sigma-Aldrich) and supplemented with $2 \mathrm{mM}$ L-glutamine $1 \%$ penicillin/streptomycin (Invitrogen Life Technologies), $0.5 \mathrm{mM}$ valproic acid (Sigma-Aldrich) and $2 \%$ NeuroBrew21 (with vitamin A, MACS Miltenyi Biotec, Bisley, Surrey, UK). Finally, neurons were plated onto $1 \mathrm{mg} /$ $\mathrm{mL}$ poly-D-lysine (PDL, Sigma-Aldrich)-coated 13-mm glass coverslips (VWR International, Lutterworth, Leicestershire, UK) at a density of approximately $\sim 1 \times 10^{5}$ cells/coverslip and were cultured in differentiation medium for up to 16 days at $37{ }^{\circ} \mathrm{C}$ in a humidified atmosphere of $5 \% \mathrm{CO}_{2} / 95 \%$ air. Differentiation medium was changed every $2-3$ days. Striatal neurons were used for further experimentation from 1 day post-plate down (dpp) onwards.

\section{Human iPSC culture, differentiation and transfection}

Two hiPSC lines were employed in this study. Firstly, the CS83iCTR33 (CTR33Qn1) line which was derived from an unaffected sibling of a patient with Huntington's disease (HD), with genotyped $C A G$ repeat lengths of 33 and 18 in the HTT gene; this line was reprogrammed using a nonintegrating strategy and was developed as a 'control' line for a related study on Huntington's disease hiPSC characterisation, similar to that already published for integrating HD hiPSC lines [25]. Secondly, the 34D6 line [2] was derived from a 'control' patient and re-programmed using integrating vectors, a kind gift of Prof. Siddharthan Chandran, University of Edinburgh.

hiPSC lines were cultured in the pluripotent state using mTeSR ${ }^{\text {TM}} 1$ (Stem Cell Technologies, Grenoble, France) on BD Matrigel-coated plates (BD Biosciences, Oxford, Oxon, UK), with dispase passaging following the manufacturer's instructions (Stem Cell Technologies). hiPSCs were differentiated to neural progenitors using an in-house, patented differentiation protocol (PCT/GB2014/053064) previously described [37], that is similar to that described for hES cells [26]. To generate ventral forebrain neural progenitors, hiPSCs were plated onto Matrigel-coated glass coverslips and transferred into SLI medium (Advanced DMEM/F12, supplemented with $2 \mathrm{mM} \mathrm{L}$-glutamine, $1 \%$ penicillin/streptomycin, 2\% NeuroBrew21 (without vitamin A), $10 \mu \mathrm{M}$ SB431542 (Abcam, Cambridge, Cambridgeshire, UK), $1 \mu$ M LDN 193189 (Stemgent, Cambridge, MA, USA) and 1.5 $\mu \mathrm{M}$ IWR1 (Tocris Bioscience, Abingdon, Oxon, UK); this point was designated as $0 \mathrm{dpp}$. Cells were cultured for 4 days in SLI medium with medium changed daily. At 5 dpp, cells were treated with $10 \mu \mathrm{M} \mathrm{Y}-27632$ (Abcam) for $1 \mathrm{~h}$ prior to passage using accutase and replating on Matrigel-coated plates with a split ratio of 1:2. At $8 \mathrm{dpp}$, cells were passaged as above and the medium was switched from SLI to LI medium (Advanced DMEM/F12, supplemented with $2 \mathrm{mM} \mathrm{L-glu-}$ tamine, $1 \%$ penicillin/streptomycin, $2 \%$ NeuroBrew2 1 
(without vitamin A), $250 \mathrm{nM}$ LDN 193189 and $1.5 \mu \mathrm{M}$ IWR1). The medium was changed daily until day $16 \mathrm{dpp}$, when neural progenitors were harvested by accutase (GE Healthcare Life Sciences, Little Chalfont, UK) treatment and centrifugation at $110 \mathrm{~g}$, and the cell pellets resuspended as a single cell suspension, and cultured on Matrigel-coated coverslips at a density of approximately $1 \times 10^{5}$ cells/coverslip in SCM1 differentiation medium (Advanced DMEM/F12, supplemented with $2 \mathrm{mM}$ L-glutamine, $1 \%$ penicillin/streptomycin, 2\% NeuroBrew21 (with vitamin A), $2 \mu \mathrm{M}$ PD0332991 (Tocris Bioscience), $10 \mu \mathrm{M}$ DAPT (Tocris Bioscience), $10 \mathrm{ng} /$ mL BDNF (MACS Miltenyi Biotec), $1 \mu \mathrm{M}$ LM22A4 (Tocris Bioscience), $10 \mu \mathrm{M}$ forskolin (Tocris Bioscience), $3 \mu \mathrm{M}$ CHIR 99021 (Tocris Bioscience), $300 \mu \mathrm{M}$ GABA (Tocris Bioscience), $1.8 \mathrm{mM} / \mathrm{L} \mathrm{CaCl}_{2}, 200 \mu \mathrm{M}$ ascorbic acid (Sigma-Aldrich)). At 23 dpp, SCM1 medium was exchanged for SCM2 (1:1 Advanced DMEM/F12: Neurobasal A (Invitrogen Life Technologies), supplemented with $2 \mathrm{mM} \mathrm{L-}$ glutamine, $1 \%$ penicillin/streptomycin, 2\% NeuroBrew21 (with vitamin A), $10 \mathrm{ng} / \mathrm{mL}$ BDNF, $1 \mu \mathrm{M}$ LM22A4, $3 \mu \mathrm{M}$ CHIR 99021, $1.8 \mathrm{mM} / \mathrm{L} \mathrm{CaCl}_{2}, 200 \mu \mathrm{M}$ ascorbic acid) and cultured in SCM2 for up to $37 \mathrm{dpp}$ with $50 \%$ medium changes every 3-4 days.

Sixteen dpp CTR33Qn1 and 34D6-hiPSC-derived neural progenitor cells were co-transfected with Kv7.2/7.3 cDNA plasmid concatemer [42] and pmax ${ }^{\circledR G F P}$ (Lonza, Cologne, Germany) at a ratio of 10:1 using the Amaxa Nucleofector human stem cell kit (Lonza), following the manufacturer's protocols. As a control, a sham transfection was performed using the empty vector. After transfection, the cells were plated and cultured in SCM1 on PDL- and Matrigel-covered glass coverslips and, after incubation for $24 \mathrm{~h}$, were transiently selected with $800 \mu \mathrm{g} / \mathrm{mL}$ G418 (Sigma-Aldrich). SCM1 was exchanged for SCM2 after $23 \mathrm{dpp}$ and cells were cultured for up to $37 \mathrm{dpp}$.

\section{Electrophysiological recordings and analyses}

Voltage and current recordings were made using conventional patch-clamp in the whole-cell configuration [15, 37]. The bath solution contained (in $\mathrm{mM}$ ) $135 \mathrm{NaCl}$ (Fisher Scientific UK Ltd, Loughborough, Leicestershire, UK), $5 \mathrm{KCl}$ (Fisher), 1.2 $\mathrm{MgCl}_{2}$ (Sigma-Alrich), $1.25 \mathrm{CaCl}_{2}$ (Sigma-Aldrich), $10 \mathrm{D}-$ glucose (Fisher) and 5 N-2-hydroxyethylpiperazine-N'-2ethanesulfonic acid (HEPES, VWR International); $\mathrm{pH}$ was adjusted to 7.4 using $5 \mathrm{M} \mathrm{NaOH}$. The pipette solution contained (in mM) $117 \mathrm{KCl}, 10 \mathrm{NaCl}, 11 \mathrm{HEPES}, 2 \mathrm{Na}_{2^{-}}$ ATP (Sigma-Aldrich), $2 \mathrm{Na}-\mathrm{GTP}$ (Sigma-Aldrich), $1.2 \mathrm{Na}_{2}$ phosphocreatine (Sigma-Aldrich), $2 \mathrm{MgCl}_{2}, 1 \mathrm{CaCl}_{2}$ and 11 ethylene-glycol-tetra-acetic acid (EGTA, Fisher); $\mathrm{pH}$ was adjusted to 7.2 with $\mathrm{KOH}$. All electrophysiological studies were performed using an Axopatch 200B amplifier and Digidata 1322A A/D interface (Axon Instruments, Forster City, CA,
USA) at a controlled room temperature of $22 \pm 0.5^{\circ} \mathrm{C}$. Recordings were digitised at $10 \mathrm{kHz}$ and low-pass filtered at $2 \mathrm{~Hz}$ using an 8-pole Bessel filter. The patch-clamp data were analysed using Clampfit 9.0, Microsoft Excel and Microcal Origin 6.0 software.

Membrane potential $(\mathrm{Vm})$ was recorded in current-clamp mode. Mean $( \pm$ SEM) membrane potential values were plotted against dpp. Neurons were coded according to the type of sAP activity that they demonstrated, defined as follows: (1) spontaneous action potentials (Spontaneous, at least 1 excursion that overshoots $0 \mathrm{mV}$ ), (2) attempted spontaneous action potentials (Attempting, significant excursions from resting $\mathrm{Vm}$ that did not reach $0 \mathrm{mV}$ ) or (3) no action potentials (Quiet, no significant excursions from resting $\mathrm{Vm}$ ). This then allowed neurons to be categorised into the three separate groups for further detailed analysis. Once Vm and spontaneous activity had been recorded, current was injected to hyperpolarize Vm to ca. $-70 \mathrm{mV}$ before $1 \mathrm{~s}$ current injection steps were imposed (from -10 to + $180 \mathrm{pA}$ ) in order to induce action potentials. Input resistance was measured from the voltage difference induced by the -10 pA current step to record induced action potential activity, which was coded as none (no significant excursions from baseline during injection), attempting single (significant excursions from baseline that do not reach $0 \mathrm{mV}$ ), single (a single excursion that overshoots $0 \mathrm{mV}$ ), attempted train (several excursions but only 1 overshoots $0 \mathrm{mV}$ ) and train (several excursions, at least 2 of that overshoot $0 \mathrm{mV}$ ). Where induced action potential trains were recorded, a spike frequency analysis was performed. Input resistance was measured from the voltage difference induced by the $-10-p A$ current step. Spike analysis was performed on the first spike of an induced action potential train using Clampfit 9; threshold was determined as the peak of the 3rd differential of voltage with respect to time during the upstroke of the action potential, and all other parameters are as defined extensively elsewhere [1].

$\mathrm{Na}^{+}$currents were recorded using a standard voltage-step protocol (holding potential of $-70 \mathrm{mV}$ followed by $80 \mathrm{~ms}$ steps from -120 to $+80 \mathrm{mV}$ in increments of $10 \mathrm{mV}$ ). For $\mathrm{Na}^{+}$current inactivation curves, cells were stepped for $200 \mathrm{~ms}$ to pre-pulse voltages of between -120 and $+80 \mathrm{mV}$ in $5 \mathrm{mV}$ step increments before being stepped for $200 \mathrm{~ms}$ to the test potential of $0 \mathrm{mV}$. Cell capacitance and series resistance were measured and compensated; series resistance was compensated 60-90\%. Pipette resistances were 8-10 M $\Omega$ when filled with the pipette solutions.

Conductances $(G)$ for activation and inactivation were calculated by dividing current by the appropriate driving force, $\left(V_{\mathrm{c}}-E_{\mathrm{Na}}\right)$, where $V_{\mathrm{c}}=$ command potential, and $E_{\mathrm{Na}}=+$ $66.7 \mathrm{mV} . G / G_{\max }$ was plotted against voltage and fitted with a Boltzmann equation using an iterative fitting routine:

$G / G_{\max }=1 /\left[1+\exp \left(V_{50}-V_{\mathrm{c}}\right) / h\right]$ 
where $G_{\max }$ is the extrapolated maximum conductance, $\mathrm{Va}_{50}$ and $\mathrm{Vi}_{50}$ are the voltages corresponding to half the maximum conductance and $h$ is the slope factor.

Multi-electrode arrays CTR33Qn1 hiPSCs at $16 \mathrm{dpp}$ were plated at a density of $150 \times 10^{3}$ cells/well onto poly-Dlysine-coated, 24-well multi-electrode arrays (MEAs) and cultured sequentially using the differentiation protocol as described above and in the previous study [37]. At $21 \mathrm{dpp}$, the medium was switched for a HEPESbuffered physiological solution containing the following (in $\mathrm{mM}$ ): $130 \mathrm{NaCl}, 3 \mathrm{KCl}, 1 \mathrm{MgCl}_{2}, 2 \mathrm{CaCl}_{2}, 10 \mathrm{D}$ glucose and 10 HEPES-NaOH at $\mathrm{pH} 7.4$, and the MEAs were placed onto the temperature-controlled $\left(37{ }^{\circ} \mathrm{C}\right)$ platform of a commercially available MEA workstation (Multichannel Systems, Reutlingen, Germany). Each well contained 12 electrodes, the activities of which were recorded simultaneously before, during and following manual addition of agonists, antagonists and toxins, as defined in the text and legends. Data were band-pass filtered between 100 and $2000 \mathrm{~Hz}$ and finally sampled at $20 \mathrm{kHz}$ using the acquisition software provided with the device. During recordings, this software detected single unit activity online and live displays of raw data, spikes per second histograms, and detected spike waveforms were available. For analysis, raw data were converted to a HDF5 file format, which was imported into the MatLab environment in which custom-written analysis routines were coded. Spikes were redetected and sorted, and time stamps were extracted allowing the various plots shown here to be produced. Root mean square recording noise levels were $\sim 1.7 \mu \mathrm{V}$. Spikes were detected using a threshold method (usually $5 \mathrm{SD}$ of the mean) that detected either rapidly rising or falling events. Amplitudes of clearly resolvable spikes uncontaminated by significant levels of false detections varied between 10 and $100 \mu \mathrm{V}$. The major source of this amplitude variation is likely to be the physical distance of each detected neuron from the recording site. Typically, spontaneous spiking activity could be detected on multiple electrodes within a single well and in 24-well plates.

Gabazine hydrobromide (SR-95531) (Tocris Bioscience) at $5 \mu \mathrm{M}$ was employed as a selective competitive antagonist of $\mathrm{GABA}_{\mathrm{A}}$ receptors [37]. Retigabine dihydrochloride (LKT Laboratories Inc., St Paul, MN, USA) at $10 \mu \mathrm{M}$ was employed as a selective opener of Kv7 channels [42]; XE991 (SigmaAldrich) at $(10 \mu \mathrm{M})$ was used as a selective blocker of Kv7 channels [40].

All data are expressed as mean \pm SEM. Statistical comparisons of the means were performed using 2-way AVOVA or Student's $t$ tests, as appropriate; differences were considered significant at $p<0.05$.
Human tissue collection, processing and data analysis

Adult motor cortical, caudate and putamen samples from 31- to 86-year-old donors were obtained from the Neurological Tissue Bank of the Biobank-Hospital Clínic (IDIBAPS) following the guidelines and approval of the local ethics committee (Hospital Clínic of Barcelona's Clinical Research Ethics Committee). Total RNA was isolated using TRI Reagent (Sigma-Aldrich) following the manufacturer's protocol. Human foetal tissue (CRL of 22$54 \mathrm{~mm}$ ) ranging in age from 7 to 9 weeks post-conception was collected by donation of the products of elective termination of pregnancy, within the MRC- and Welsh Government-sponsored South Wales Initiative for Foetal Tissue Transplantation ('SWIFT') programme, with full ethical approval (02/4446). Tissue was collected directly into hibernation medium at $4{ }^{\circ} \mathrm{C}$ and transported to Cardiff University where it was dissected under category II culture conditions, according to a previously published protocol [19]. Cortex and striatal primordia were dissected in $0.9 \%$ saline solution with addition of $0.6 \%$ glucose (hospital pharmacy) and stored individually in TRIzol (Invitrogen Life Technologies) at $-80{ }^{\circ} \mathrm{C}$ until use. Total RNA was isolated using TRI Reagent (Sigma-Aldrich) or TRIzol following the manufacturer's protocol. Then, $10 \mu \mathrm{L}$ of total RNA at a concentration of $200 \mathrm{ng} / \mu \mathrm{L}$ ( $2 \mu \mathrm{g}$ in total) for each sample was reverse-transcribed with random primers using High-Capacity RNA-to-cDNA Kit (Invitrogen Life Technologies); $10 \mu \mathrm{L}$ of retro-transcription cocktail $(2 \mu \mathrm{L}$ of $10 \times \mathrm{RT}$ buffer, $2 \mu \mathrm{L}$ pf Random primers, $1 \mu \mathrm{L}$ of dNTP mix; $1 \mu \mathrm{L}$ MultiScribe reverse transcriptase) was added to each sample ( $20 \mu \mathrm{L}$ total volume). After gentle mixing, samples were incubated for $10 \mathrm{~min}$ at room temperature followed by $2 \mathrm{~h}$ at $37^{\circ} \mathrm{C}, 10 \mathrm{~min}$ on ice and $10 \mathrm{~min}$ at $75^{\circ} \mathrm{C} ; 10 \mathrm{ng}$ of cDNA was used to perform quantitative realtime PCR (qPCR). PrimeTime qPCR assays were used as recommended by the provider (IDT Technologies, Leuven, Belgium). RPL13A, B2M and HSP90 mRNA levels were used as reference genes. qPCR was carried out with Premix Ex Taq (Takara Clontech, Saint-Germain-en-Laye, France) in $6 \mu \mathrm{L}$ of final volume using CFX384-C1000 Thermal Cycler equipment (Bio-Rad). Samples were run for 40 cycles $\left(95^{\circ} \mathrm{C}\right.$ for $5 \mathrm{~s}, 60^{\circ} \mathrm{C}$ for $20 \mathrm{~s}$ ). Relative gene expression values were calculated using the $2^{-\Delta \Delta \mathrm{Ct}}[22]$ using Bio-Rad CFX manager software (Bio-Rad, Madrid, Spain). All data are expressed as mean \pm SEM. Data were analysed using GraphPad 4.02. Statistical comparisons of the means were performed using two-tailed, unpaired $t$ test; differences were considered significant at $p<0.05$.

\section{Mouse tissue collection and processing for microarrays and qPCR}

C57/B16 mice (Charles River Laboratories, Les Oncins, France) were maintained in standard conditions with food and water ad libitum. All animal procedures were approved by local committees, in accordance with the 
European Communities Council Directive (86/609/EU). The day of pregnancy, determined by the first detection of a vaginal sperm plug in daily inspection, was considered embryonic day (E) 0.5. Briefly, brains were removed, frozen and embedded before sections were cut using a cryostat, and after cresyl violet staining, the two different zones of the lateral ganglionic eminence (LGE) germinal zone (GZ) and mantle zone (MZ) were microdissected using the Leica Laser Microdissection Microscope D7000. RNA extraction of the collected samples was carried out with the RNeasy Micro Kit (Qiagen). Microarrays were run using the Affymetrix MouseGene ST v1.1 chip to analyse 32 mRNA samples (5-4 samples per condition). To validate the dynamics of Kv7.2 (KCNQ2) and Kv7.3 (KCNQ3) gene expression during mouse embryonic development, mRNA levels of both channels were analysed by qPCR at different developmental stages (E12.5, E14.5, E16.5 and E18.5) and in the different striatal zones (LGE for E12.5, GZ and MZ for the other stages). Expression of mRNA encoding $K N C Q$ channels in embryonic mouse striatal (mSTM) neurons was determined by qPCR (see above, for conditions). All data are expressed as mean \pm SEM. Data were analysed using GraphPad 4.02. Statistical comparisons were made by two-way analysis of variance (ANOVA) followed by Bonferroni post-test. Values of $p<0.05$ were considered statistically significant.

\section{Immunocytochemistry}

Cells were fixed with $4 \%$ paraformaldehyde in PBS (Invitrogen Life Technologies) for $15 \mathrm{~min}$ at $37{ }^{\circ} \mathrm{C}$. Cells were washed $(3 \times)$ for 5 min, blocked and permeabilised using PBS containing 1\% BSA $(w / v)$ $0.1 \%$ Tween-20 for $1 \mathrm{~h}$ at room temperature before being incubated overnight at $4{ }^{\circ} \mathrm{C}$ in rabbit primary antibody solutions (anti-KCNQ2 at 1:100 (Abcam, ab22897); antiKCNQ3 at 1:100 (Aviva Systems Biology Corporation, San Diego, CA, USA, OAAF00246)). Controls, where primary antibodies were omitted, were included for all experimental sets. After overnight incubation, the primary antibody solution was removed and the cells were washed for $5 \mathrm{~min}$ in PBS $(3 \times)$ before incubation for $1 \mathrm{~h}$ with fluorophore-conjugated secondary antibody (Alexa Flour-488, goat anti-rabbit, Life Technologies) at room temperature in the dark. Nuclear staining employed Hoechst stain (Life Technologies) at 1:5000 in PBS. Coverslips were mounted in Fluoromount $G$ (eBioscience, Hatfield, Hertfordshire, UK) and imaged using Olympus BX61 with SIS F-view charge-coupled device (CCD) camera and AnalySIS imaging software (Olympus, Southend-on-Sea, Essex, UK).

\section{Results}

\section{Development of $\mathrm{Vm}$ and expression of Kv7.2 and Kv7.3 subunits during in vivo and in vitro maturation of mouse striatal neurons}

During the first dpp in vitro, mean Vm values of mouse striatal neurons isolated at embryonic stages E15 and E17 were significantly different $(p<0.001)$ from that of E13 neurons, but not significantly different from each other: $\mathrm{E} 13=-24.8 \pm$ $2.3 \mathrm{mV}(n=26), \mathrm{E} 15=-40.0 \pm 2.2 \mathrm{mV}(n=12)$ and $\mathrm{E} 17=$ $-47.2 \pm 2.4 \mathrm{mV}(n=9)$. These data suggest that the most important stage in the early development of a hyperpolarized $\mathrm{Vm}$ in vivo takes place between E13 and E15 (Fig. 1a, b). Over the next $6 \mathrm{dpp}$, mouse striatal neurons isolated at all three stages displayed a steady hyperpolarization to between -50 and $60 \mathrm{mV}$, with only modest hyperpolarization occurring thereafter up to $15 \mathrm{dpp}$ (Fig. 1a, b). Mean Vm values of each group, at either 7 or $15 \mathrm{dpp}$, were not significantly different from each other (Fig. 1b).

Since one of the most important mechanisms responsible for setting and maintaining of $\mathrm{Vm}$ in the neurons is represented by Kv7 channels [3, 4, 18, 24], the expression of the Kv7.2 and $\mathrm{Kv} 7.3$ protein subunits was determined using immunocytochemistry in neurons isolated at E13 and cultured for up to $14 \mathrm{dpp}$. During in vitro differentiation and maturation, neurons became more complex and demonstrated a timedependent expression of both Kv7.2 (Fig. 1c, left panel) and Kv7.3 (Fig. 1c, right panel) in processes and somata; no staining was observed in the negative control when the primary antibody was omitted (not shown).

\section{Ontogeny of KCNQ (Kv7) subunits in developing mouse and human striatum}

Having established that $\mathrm{Vm}$ and level of Kv7 channel subunit expression were subjects to developmental regulation, the ontogenies in vivo of the genes $K C N Q 2$ and $K C N Q 3$ (which encode Kv7.2 and Kv7.3 subunits, respectively) were determined in laser-microdissected mouse striata. Developmental time points of E12.5 (LGE) through E18.5 (GZ and MZ) were employed. For $K C N Q 2$ mRNA in vivo, two-way AVOVA highlighted an overall difference between GZ and MZ $(p<$ $0.01)$, with a specific enrichment observed at E14.5 $(p<0.02$, Fig. 2a). For $K C N Q 3$ mRNA, a similar analysis demonstrated regional differences $(p<0.001)$, with enrichments at E14.5 ( $p$ $<0.05)$, E16.5 $(p<0.01)$ and E18.5 $(p<0.01$, Fig. $2 b)$. Comparisons of mRNA levels in each zone with LGE demonstrated that the $K C N Q 2$ did not significantly alter during development in either zone (Fig. 2c). In contrast, $K C N Q 3$ steadily increased during development in the MZ (Fig. 2d). Thus, consistent with the electrophysiological observations, these data show that mRNA encoding both $K C N Q 2$ and 
$K C N Q 3$ becomes enriched in the post-mitotic MZ. Furthermore, they also suggest that the developmentally upregulated function of $\mathrm{Kv} 7$ channels is not a direct consequence of differential transcription of the $K C N Q 2$ gene but that of genes encoding other Kv7 subunits, such as $K C N Q 3$ (as shown in Fig. 2b, d), or even KCNQ4 and KCNQ5 (Fig. 3).

Further investigation of this idea was carried out by employing qPCR to quantify the expression of other $K C N Q$ genes in mouse striatal neurons isolated between E13 and E17 and cultured for up to 7 DIV which, as a group, increased significantly $(p<0.001)$ between 1 and 7 dpp. Specifically, at $1 \mathrm{dpp}, K C N Q 2$ mRNA was expressed at similar levels across all developmental time points (Fig. 3a). However, $K C N Q 3$ mRNA (along with those for $K C N Q 4$ and $K C N Q 5$ ) was upregulated between $\mathrm{E} 13$ and $\mathrm{E} 15(p<0.05$ for $K C N Q 3$ and $K C N Q 5, p<0.01$ for $K C N Q 4$, Fig. 3a); thereafter, $K C N Q 4$ and $K C N Q 5$ expression declined whilst $K C N Q 3$ was sustained (Fig. 3a). During differentiation and maturation in vitro, a slightly different early pattern of mRNA expression was observed, with both $K C N Q 2$ and $K C N Q 3$ mRNA in mouse striatal neurons isolated at E13 increasing between 1 and $7 \mathrm{dpp}(p<0.05$, Fig. 3b); mRNA encoding KCNQ4 and
Fig. 1 Ontogeny of membrane potential and $K v 7.2$ and $K v 7.3$ channel protein expression in mouse striatal neurons isolated at embryonic stages E13, E15 and $\mathrm{E} 17$ and differentiated in vitro. a Exponential fits of membrane potential $(\mathrm{Vm})$ changes in mouse striatal neurons isolated at embryonic stages E13 (black circles), E15 (grey triangles) and E17 (empty squares) and cultured for up to 15 days post-plate down (dpp). The dashed boxes represent the time windows for which the analyses in $\mathbf{b}$ have been derived. $\mathbf{b}$ Bar charts presenting means of Vm measured in mouse striatal neurons isolated at the embryonic stages indicated above each bar (E13 (black), E15 (grey) and E17 (white)) and assayed at $1 \mathrm{dpp}$ (left), $7 \mathrm{dpp}$ (centre) and $14 \mathrm{dpp}$ (right). Number of observations shown in parentheses. Significant differences, determined by unpaired Student's $t$ test, are shown below the bars, where appropriate; $* * * * p<0.0001$. c Kv7.2 (left panels, $\times 20$ and $\times 100$, as indicated) and Kv7.3 (right panels, $\times 20$ and $\times 100$, as indicated) protein expression by immunocytochemistry in E15 mouse striatal neurons during in vitro maturation at 1,7 and $14 \mathrm{dpp}$ a

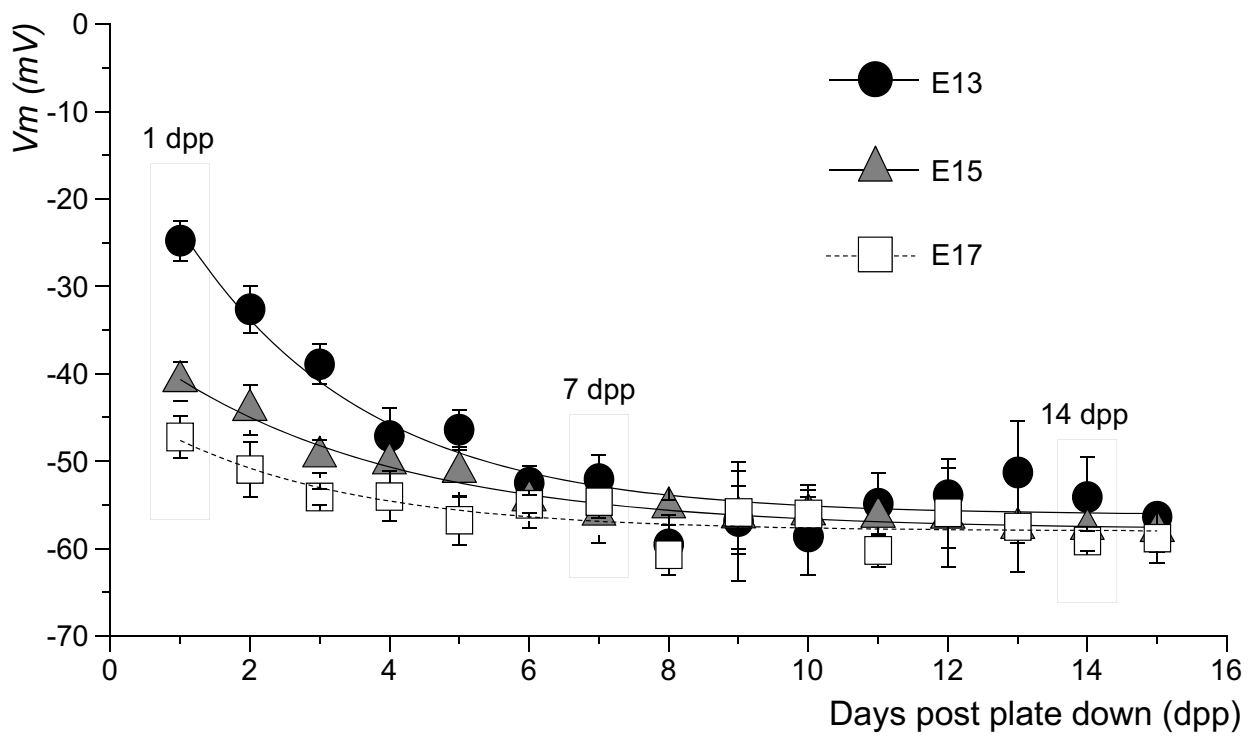

b

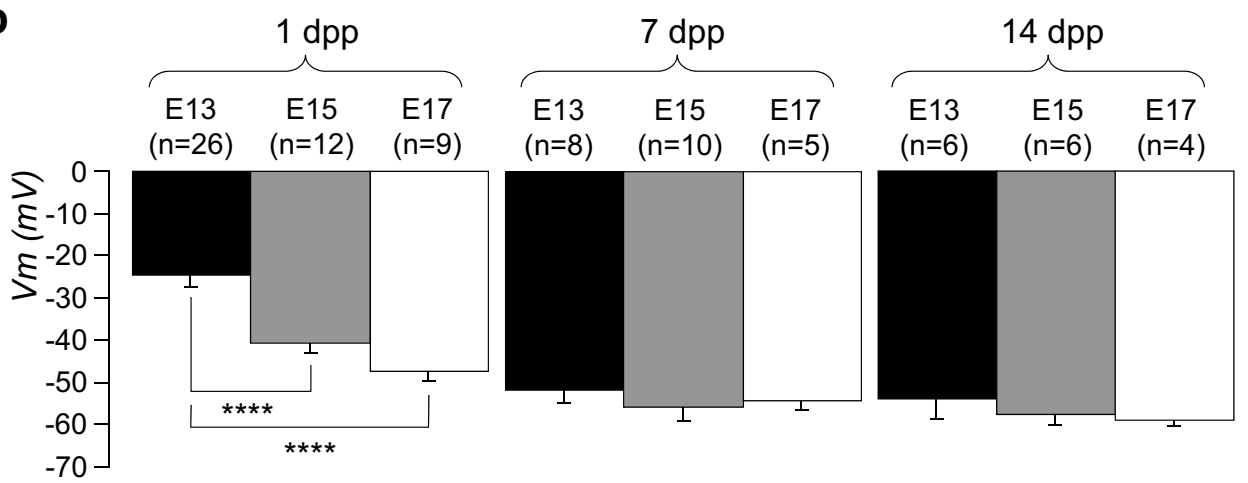

C
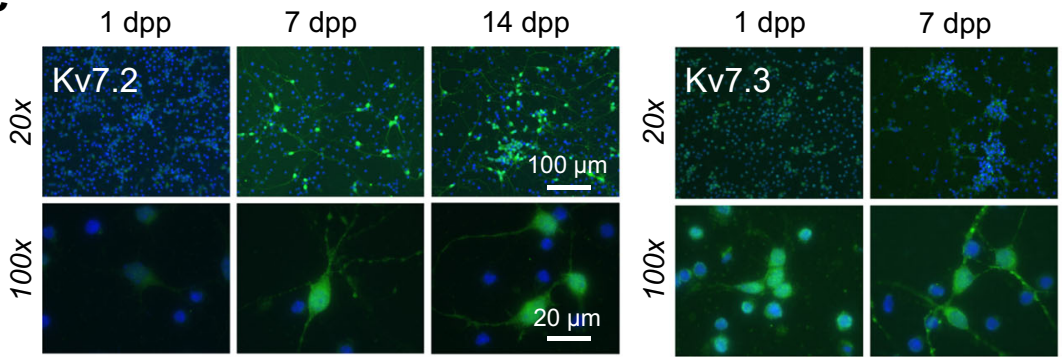

14 dpp
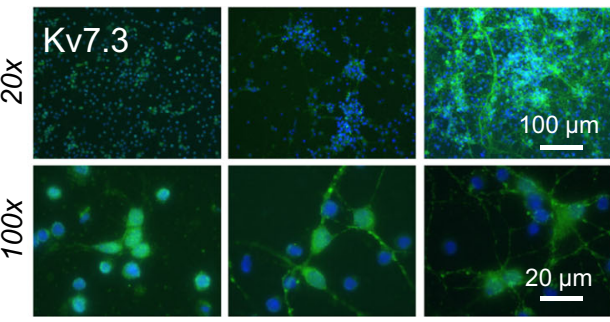
a

KCNQ2

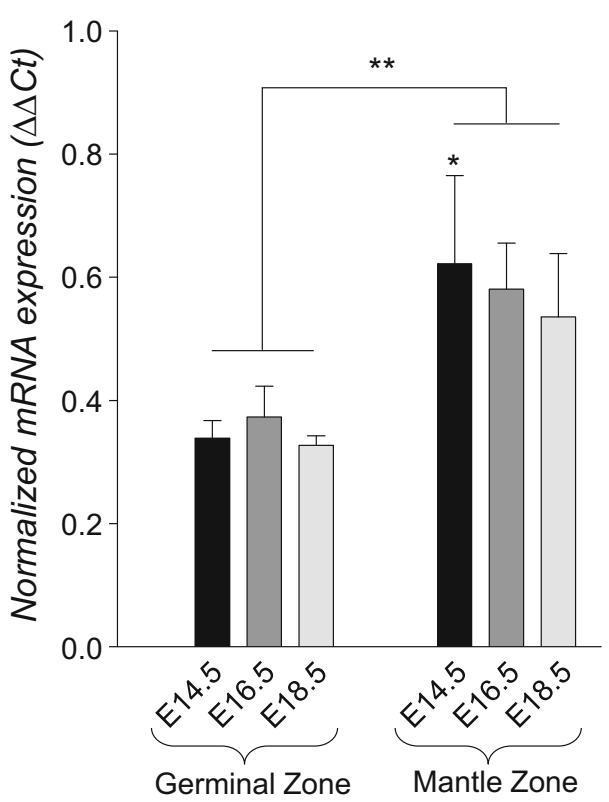

C

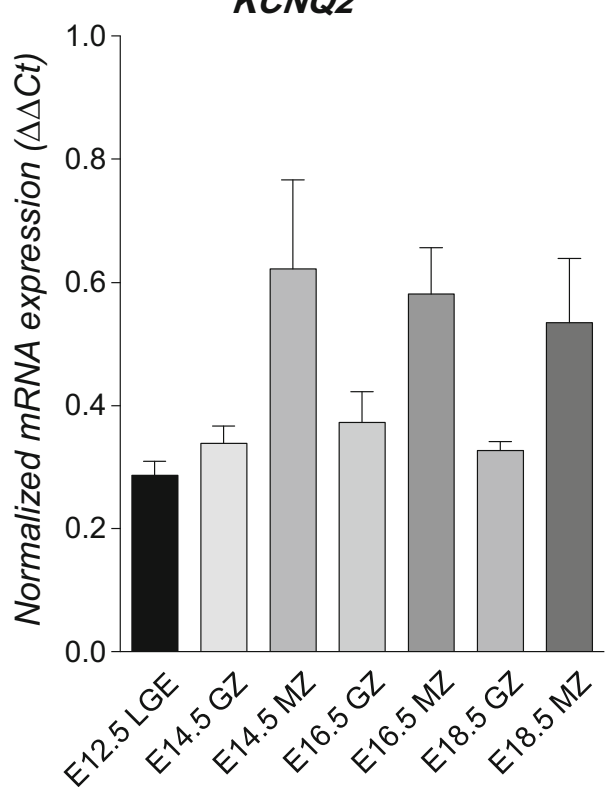

Fig. 2 Ontogeny of $K C N Q 2$ and $K C N Q 3$ mRNA expression in developing mouse striatum in vivo. a $K C N Q 2 \mathrm{mRNA}$ expression during mouse striatal development in vivo. In $\mathbf{a}$ and $\mathbf{b}, \mathrm{mRNA}$ levels were determined in laser-microdissected mouse striatal regions by qPCR and were normalised to the house-keeping genes (18S/ $\beta$-actin) using the $\Delta \Delta \mathrm{Ct}$ method. By two-way ANOVA, there was a significant difference between $K C N Q 2$ mRNA in mantle zone (MZ) and germinal zone (GZ), $* * p<0.01$, with a significant enrichment in MZ at E14.5, asterisk above the $\mathrm{MZ}$ bar, ${ }^{*} p<0.05$. b $K C N Q 3$ mRNA expression during mouse striatal development in vivo. By two-way ANOVA, there were significant regional differences, $* * * p<0.001$, with significant enrichments in the MZ at E14.5, E16.5 and E18.5, asterisks above the

\section{b \\ KCNQ3}

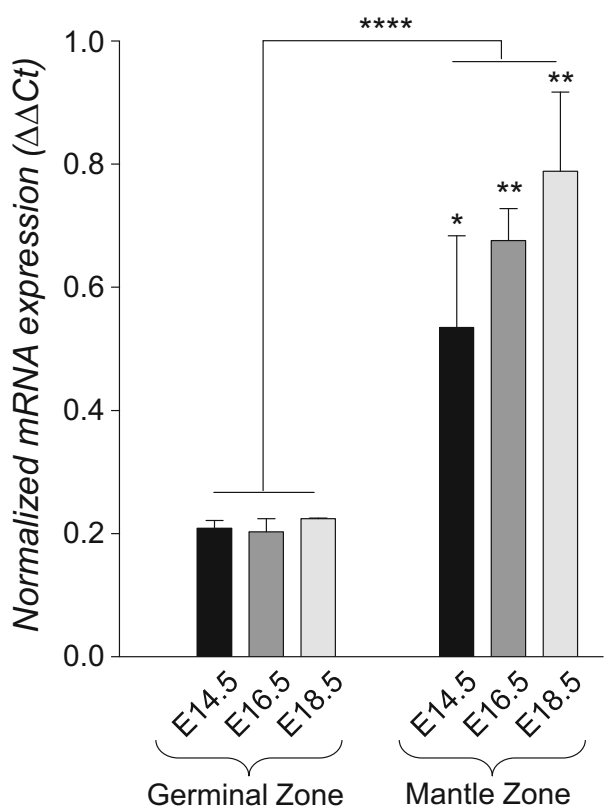

d

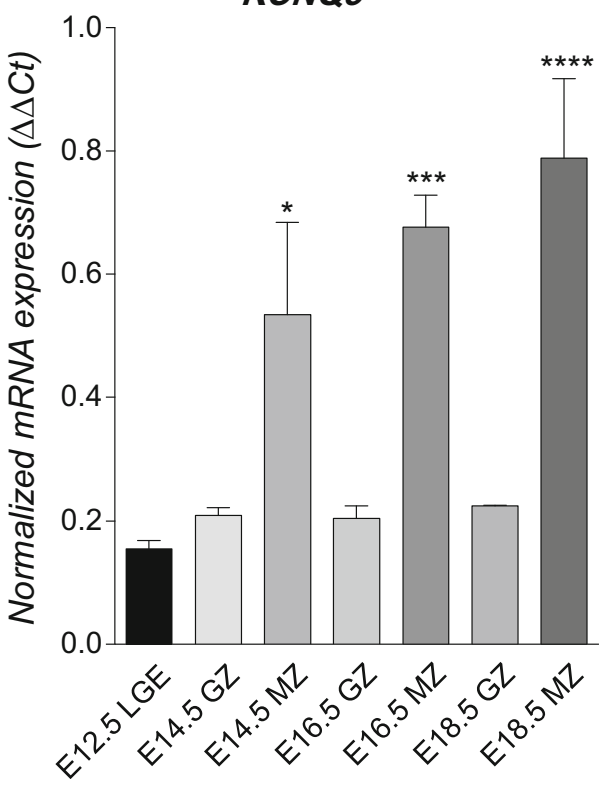

MZ bars, $* p<0.05, * * p<0.01$. c KCNQ2 mRNA expression during mouse striatal development in vivo. For $\mathbf{c}$ and $\mathbf{d}, \mathrm{mRNA}$ levels in lasermicrodissected mouse striatal regions were determined by qPCR and were normalised to the house-keeping genes $(18 \mathrm{~S} / \beta$-actin) using the $\Delta \Delta \mathrm{Ct}$ method. Data were analysed by one-way ANOVA with Tukey's post hoc test, and showed that, compared to LGE, KCNQ2 mRNA levels in each zone did not significantly alter during development in either zone. d $K C N Q 3$ mRNA expression during mouse striatal development in vivo. Data were analysed by one-way ANOVA with Tukey's post hoc test, and showed that, compared to LGE, KCNQ3 mRNA in the MZ was shown to increase steadily during development. $* p<0.05$, $* * * p<0.001$, $* * * * p<0.0001$ 
KCNQ5 demonstrated no significant changes during in vitro differentiation (Fig. 3b).

Finally, we sought to determine whether the overall pattern of $K C N Q / \mathrm{Kv} 7$ expression that was observed in mouse was reflective of the situation in human development. To this end, cryosections were cut from human foetal brain samples collected 7-9 weeks post-conception, when developing striatum is effectively the whole ganglionic eminence (WGE) and $K C N Q$ mRNA levels compared with post-mortem adult striatum. KCNQ2 mRNA was expressed at similar levels between the stages (Fig. 3c). Strikingly, and similar to the pattern seen in developing mouse striatum, $K C N Q 3$ was significantly enriched in the striatum, as were $K C N Q 4$ and $K C N Q 5$
(Fig. 3c). These data, which demonstrate the enrichment of subunits which constitute Kv7 channels in the post-mitotic neuronal compartments of the developing striatum of mouse and human in vivo, and the broadly similar pattern which is seen when mouse striatal neurons are differentiated in vitro, correlate well with the functional data showing developmentally regulated progressive hyperpolarization of Vm (see Fig. 1).

\section{Expression of KCNQ and Kv7 channel subunits during neuronal differentiation of hiPSCs}

Although there have been observations that $\mathrm{Kv} 7$ channels contribute to the excitability of hiPSC-derived neurons [44],
Fig. 3 Ontogeny of $K C N Q$ mRNA expression in developing mouse and human striatum. a $K C N Q$ mRNA expression in mouse striatal neurons during development in vivo. mRNA levels were determined in mouse striatal neurons isolated at E13, E15 and E17 by qPCR and were normalised to the house-keeping genes $(18 \mathrm{~S} / \beta$-actin) using the $\Delta \Delta \mathrm{Ct}$ method. By one-way ANOVA (Tukey's post hoc), there were significant differences between KCNQ mRNA at E15 and E17 with its own control at E13, $p<0.05$. b $K C N Q$ mRNA expression in E13 mouse striatal neurons during in vitro differentiation and maturation. By one-way ANOVA (Tukey's post hoc), there were significant differences of $K C N Q 2$ and $K C N Q 3$ mRNA between 1 and 7 dpp, $p<0.05$. c $K C N Q$ mRNA expression during human striatal development in vivo. mRNA levels in human striatal regions dissected from cryosections were determined by qPCR and were normalised to house-keeping genes (RPL13A and HSP9OABI) using the $\Delta \Delta \mathrm{Ct}$ method. By unpaired Student's $t$ test, there were significant differences between whole ganglionic eminence (WGE, 7-9 weeks postconception) and adult striatum expression of $K C N Q 3, K C N Q 4$ and KCNQ5 mRNA, * $p<0.05$
Mouse neurons $1 \mathrm{dpp}$

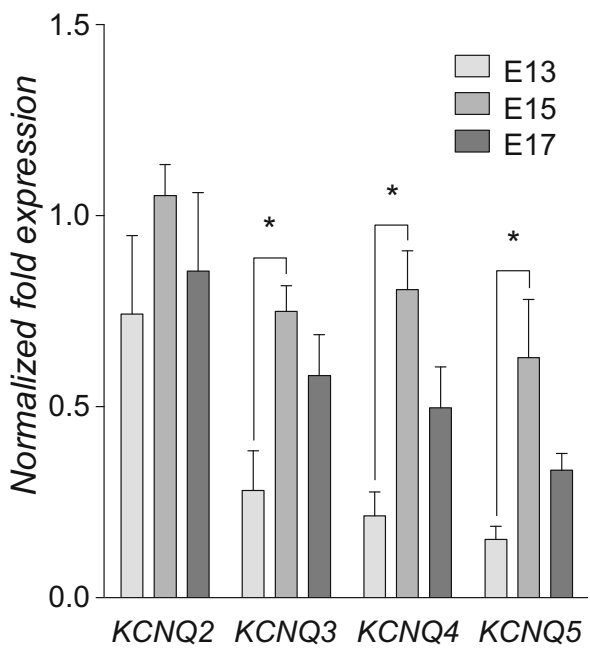

b

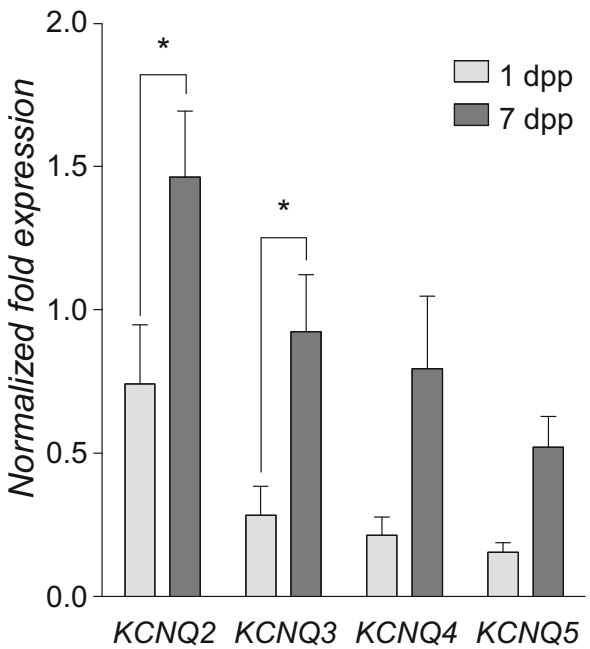

C

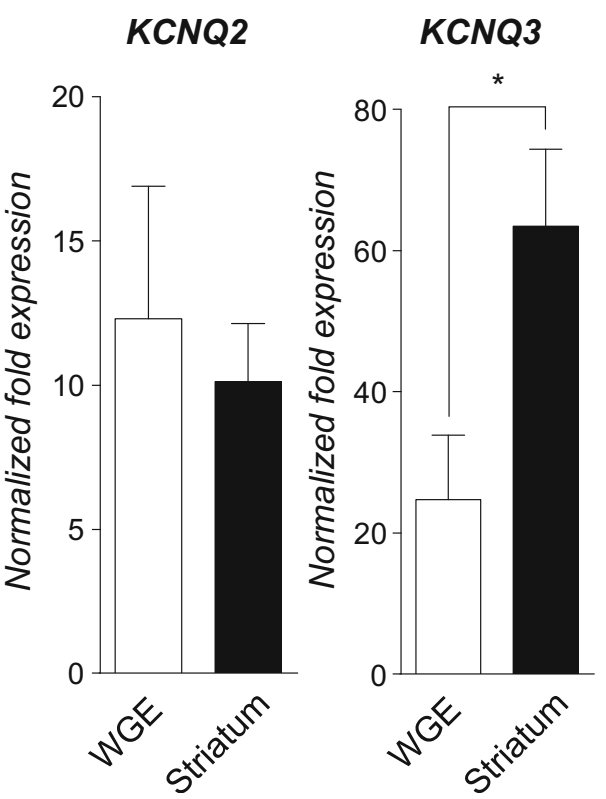

Human striatal development

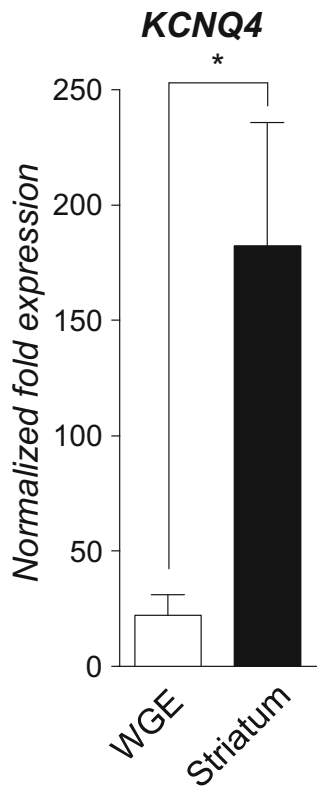

KCNQ5

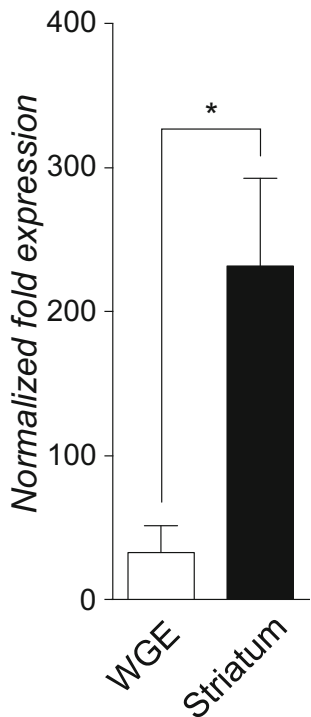


none have investigated directly the correlation between expression of Kv7 subunits, hyperpolarization of Vm and excitability during differentiation of hiPSCs, especially those prepatterned to ventral forebrain precursors. Therefore, using the hiPSCs pre-patterned by an established technique of dual SMAD and Wnt inhibition [20, 26, 37], a detailed determination of both the expression of $K C N Q$ mRNA and $\mathrm{Kv} 7$ subunits in these developing striatal-like neurons was performed using the control hiPSC line, CS83iCTR33Qn1 (CTR33Qn1). KCNQ2 and KCNQ5 mRNA both increased early (23 dpp), whilst $K C N Q 3$ and $K C N Q 4$ showed no significant differences during the differentiation protocol. Uniquely,
Fig. 4 Ontogeny of $K C N Q$ mRNA and Kv7 channel protein expression during neuronal differentiation of CTR33Qn1 hiPSC-derived neurons. a Ontogeny of $K C N Q 2$ (upper left), $K C N Q 3$ (upper right), $K C N Q 4$ (lower left) and $K C N Q 5$ (lower right) mRNA expression during neuronal differentiation of CTR33Qn1 hiPSC-derived neurons from prepatterned forebrain progenitors (16 dpp) to maturation (37 dpp). mRNA levels were determined by qPCR, were normalised to the house-keeping genes ( $B 2 M$, $R P L 13 A$ and HSP90AB1) using the $2^{-\Delta \Delta \mathrm{Ct}}$ method and expressed as a level relative to $16 \mathrm{dpp}$. Data were analyses by one-way AVOVA followed by Tukey's post hoc test. Differences from 16 dpp are shown, $* * p<0.01$, $* * * p<0.001$. b Comparison of mean $\triangle \mathrm{Ct}$ values of each $K C N Q$ during CTR33Qn1 hiPSC neuronal differentiation. $K C N Q 2$ and $K C N Q 3$ values were significantly lower than $K C N Q 4$ or $K C N Q 5$, indicating that the former are expressed at a higher level than the latter. Two-way ANOVA, $p<0.001$. c Immunocytochemistry showing expression of Kv7.2 (left) and Kv7.3 (right) protein in CTR33Qn1 hiPSC-derived neurons at $19 \mathrm{dpp}$ and $31 \mathrm{dpp}$ during neuronal differentiation, at $\times 20$ and $\times 100$, as indicated
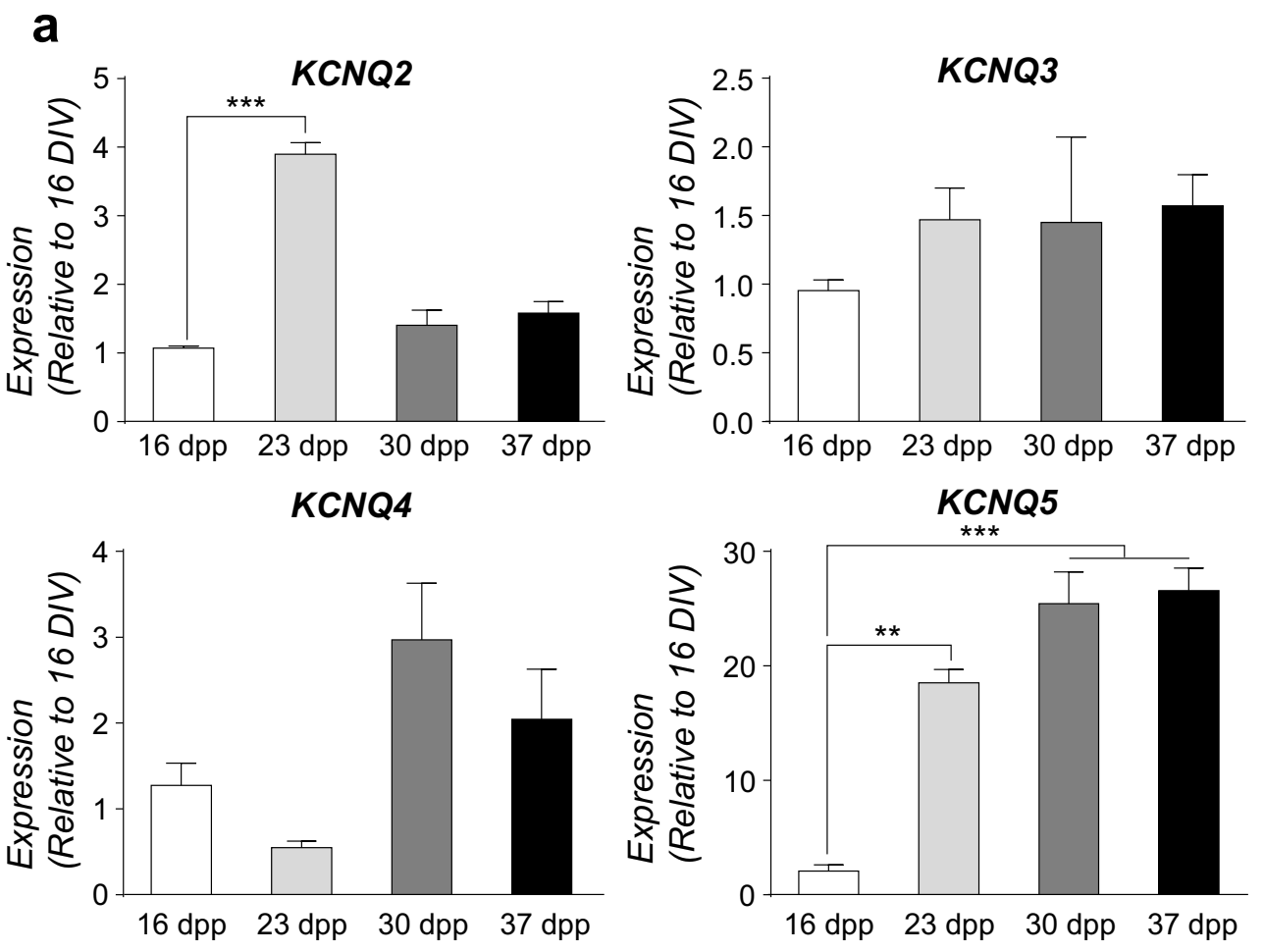

b

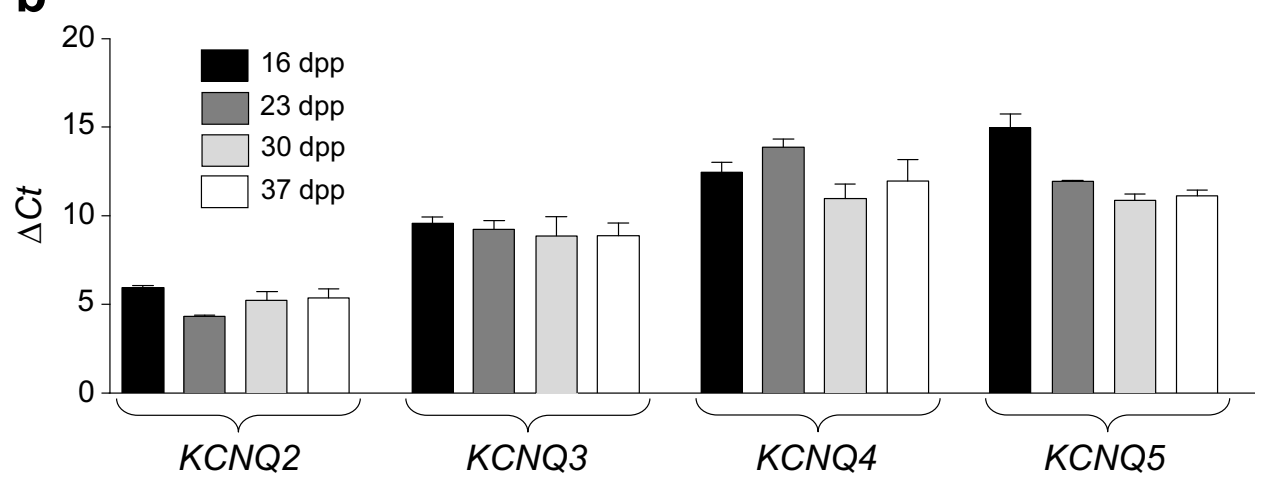

C
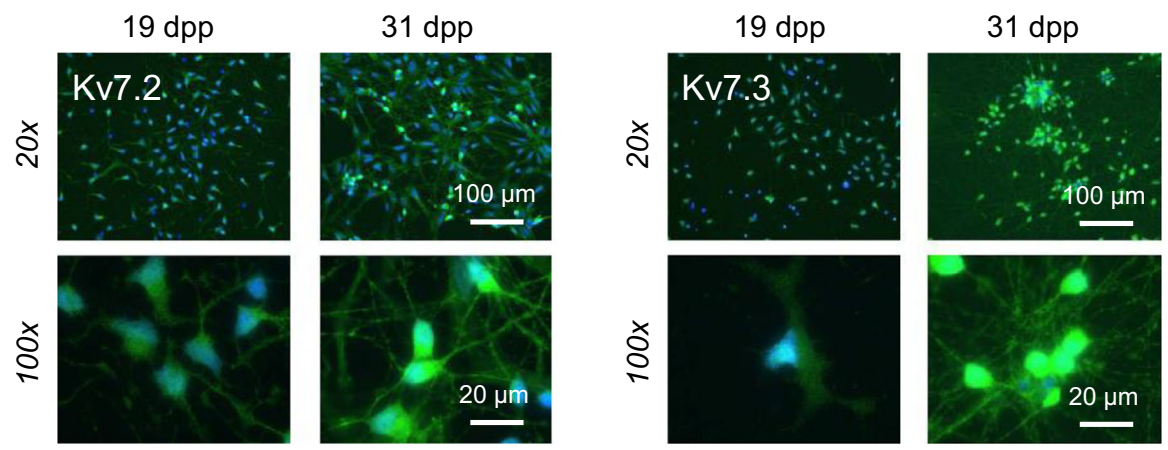
$K C N Q 5$ remained elevated, whilst $K C N Q 2$ expression waned from $30 \mathrm{dpp}$ onwards (Fig. 4a). With respect to absolute quantitation of $K C N Q$ mRNA, $K C N Q 2$ and $K C N Q 3$ were expressed at significantly $(p<0.001)$ higher levels than a Control Gabazine
$5 \mu \mathrm{M}$
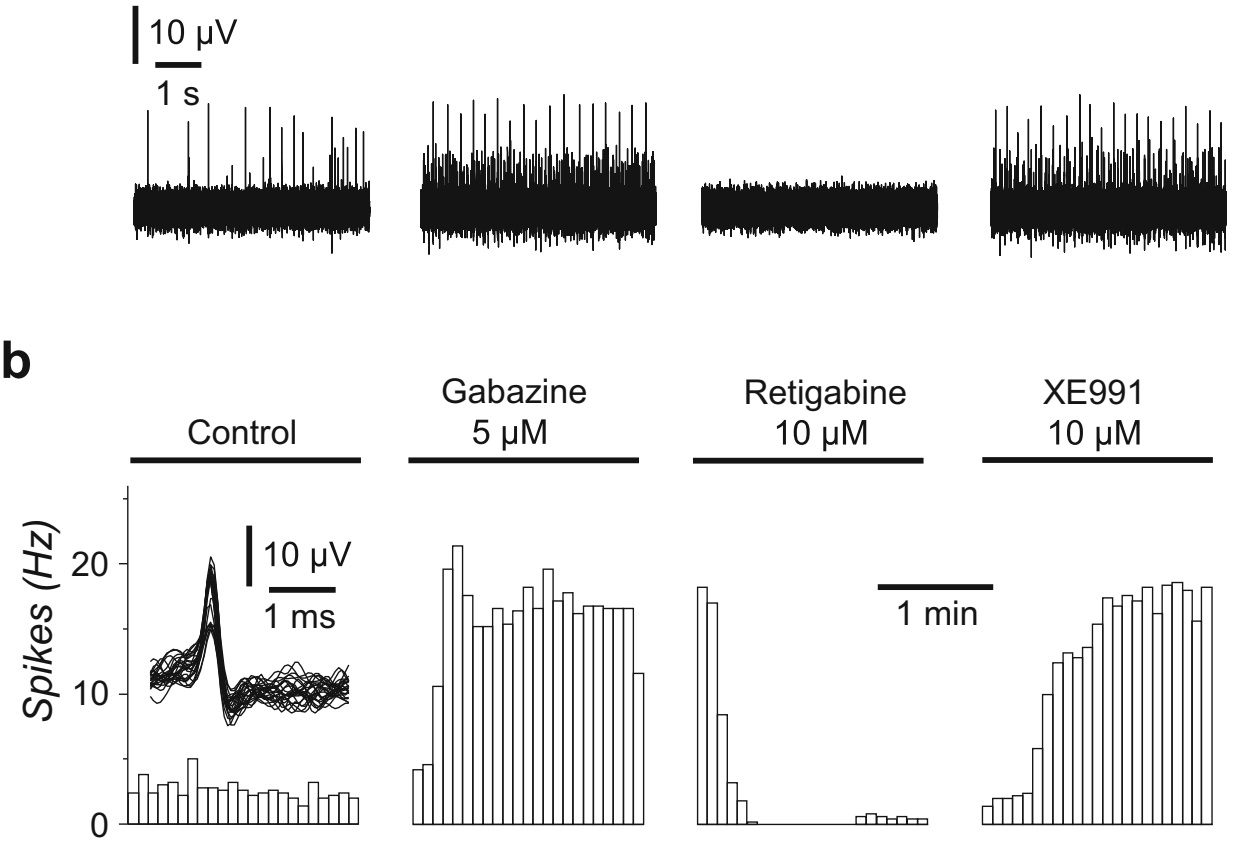

Retigabine
$10 \mu \mathrm{M}$

\section{XE991 \\ $10 \mu \mathrm{M}$}

\section{b \\ b}
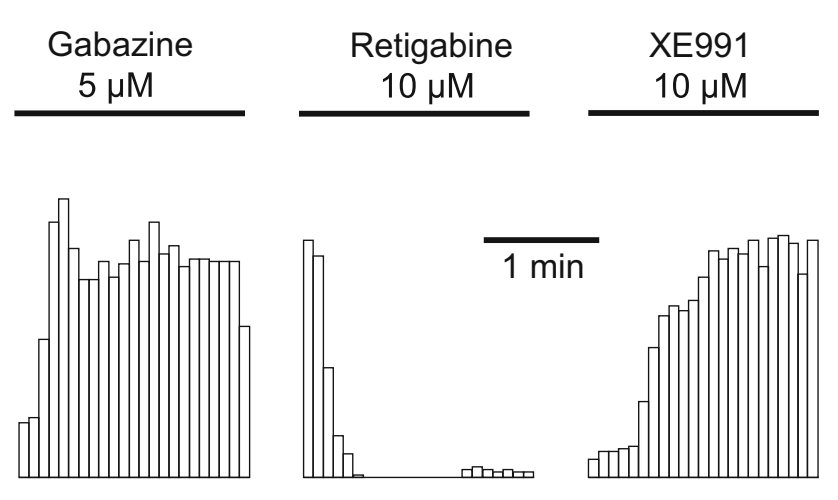

$c$

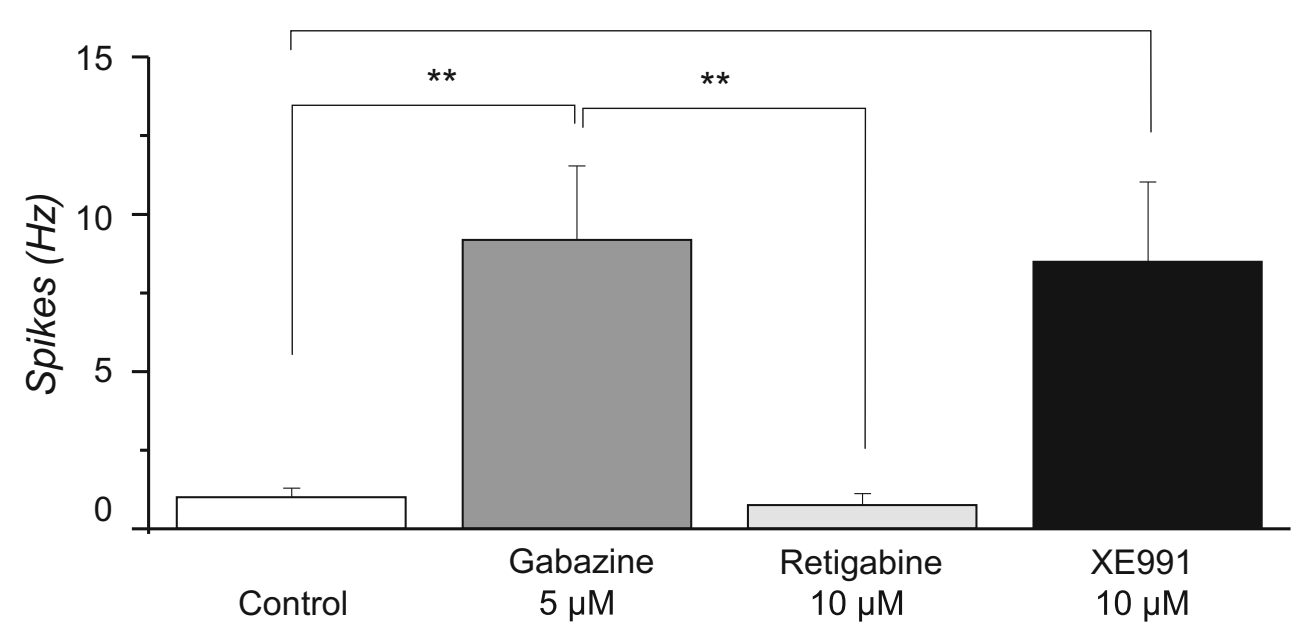

Fig. 5 Spontaneous unit responses recorded from CTR33Qn1 hiPSCderived neurons plated in 24-well multi-electrode arrays (MEAs). a Exemplars of 5-s snapshots of raw data taken from one electrode (position 24) within one MEA well. The first recording (left) is in the absence of drugs. The subsequent recordings (right) are in the presence of $\mathrm{GABA}_{\mathrm{A}}$ receptorantagonist gabazine $(5 \mu \mathrm{M}), \mathrm{Kv} 7$ channel opener retigabine $(10 \mu \mathrm{M})$ and Kv7 channel selective blocker XE991 $(10 \mu \mathrm{M})$. b Histograms of spike rate versus time for unit responses detected from individual MEA electrodes. Four consecutive 120-s recording epochs are shown from two electrodes, position 24 (top) and position 43 (bottom). The first epoch is in the absence of drugs. The inset shows 25 superimposed units detected during the first epoch. Drugs

were applied immediately before the recording. Gabazine $(5 \mu \mathrm{M})$ was applied initially to increase spontaneous activity of CTR33Qn1 hiPSC-derived neurons. Retigabine $(10 \mu \mathrm{M})$ eliminated spiking and XE991 $(10 \mu \mathrm{M})$ restored spiking to a rate similar to that observed before introduction of retigabine. c Bar charts presenting means of spike frequency $\pm \mathrm{SEM}$ measured in CTR33Qn1 hiPSC-derived neurons displayed significant difference, determined by paired Student's $t$ test, in the presence of gabazine, retigabine and XE991 $(* * p<0.01)$ compared to the control in the absence of drugs. A total of 11/12 electrodes detected units in this well and all responded to retigabine. In 7 instances, activity returned in the presence of XE991 
KNCQ4 and KCNQ5 throughout the neuronal differentiation period (Fig. 4b), suggesting that these two subunits may contribute a quantitatively larger proportion to the outward current, a notion supported by the robust expression of Kv7.2 and Kv7.3 proteins during the differentiation protocol (Fig. 4c).

Spontaneous neural network activity that CTR33Qn1 hiPSC-derived neurons developed between 30 and $37 \mathrm{dpp}$ was recorded using MEAs. In the control, spontaneous neuronal firing was $1.0 \pm 0.3 \mathrm{~Hz}(n=12)$, and similar to our previous study [37], pharmacological inhibition of $\mathrm{GABA}_{\mathrm{A}}$ receptors with gabazine $(5 \mu \mathrm{M})$ resulted in a continuous and significant increase in the rate of neuronal firing to $9.2 \pm$ $2.3 \mathrm{~Hz}(n=12$; vs. control $p<0.01)$ (Fig. 5). Retigabine $(10 \mu \mathrm{M})$ suppressed gabazine induced firing to $0.8 \pm 0.4 \mathrm{~Hz}$
Fig. 6 Forced expression of Kv7.2/7.3 channel subunits facilitates functional maturation of in CTR33Qn1 hiPSC-derived neurons. a Exemplar traces of current-clamp recordings (injected current $=$ $0 \mathrm{pA}$ ) for CTR33Qn1 hiPSCderived neurons exemplifying the model activity of no activity (Quiet), attempting activity (Attempting) or spontaneous activity (Spontaneous). b Bar graphs showing percentage of CTR33Qn1 hiPSC-derived neurons exhibiting no activity (Quiet), attempting activity (Attempting) or spontaneous activity (Spontaneous) (black bars, left $y$-axis) and their mean $\mathrm{Vm}$ (open bars, right $y$-axis) in sham-transfected (left panels) and Kv7.2/7.3 co-transfected CTR33Qn1 hiPSC-derived neurons (right panels) following 1, 2 and 3 weeks of in vitro neuronal differentiation a
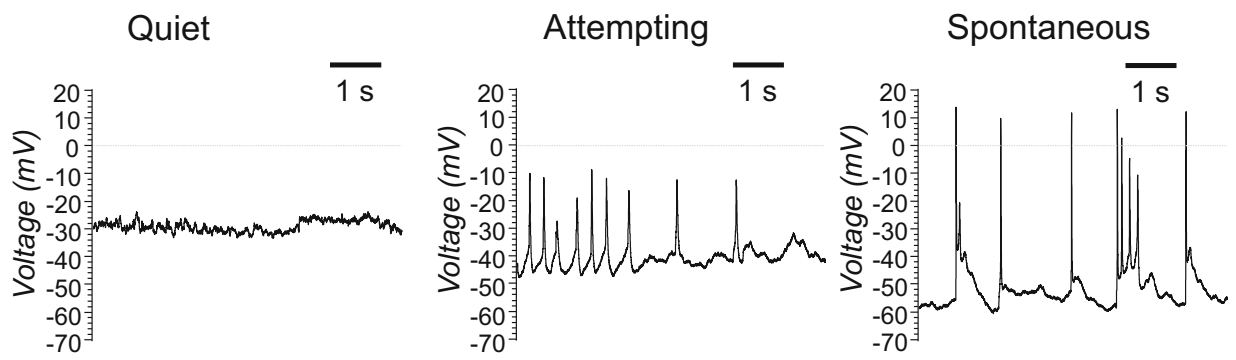

b
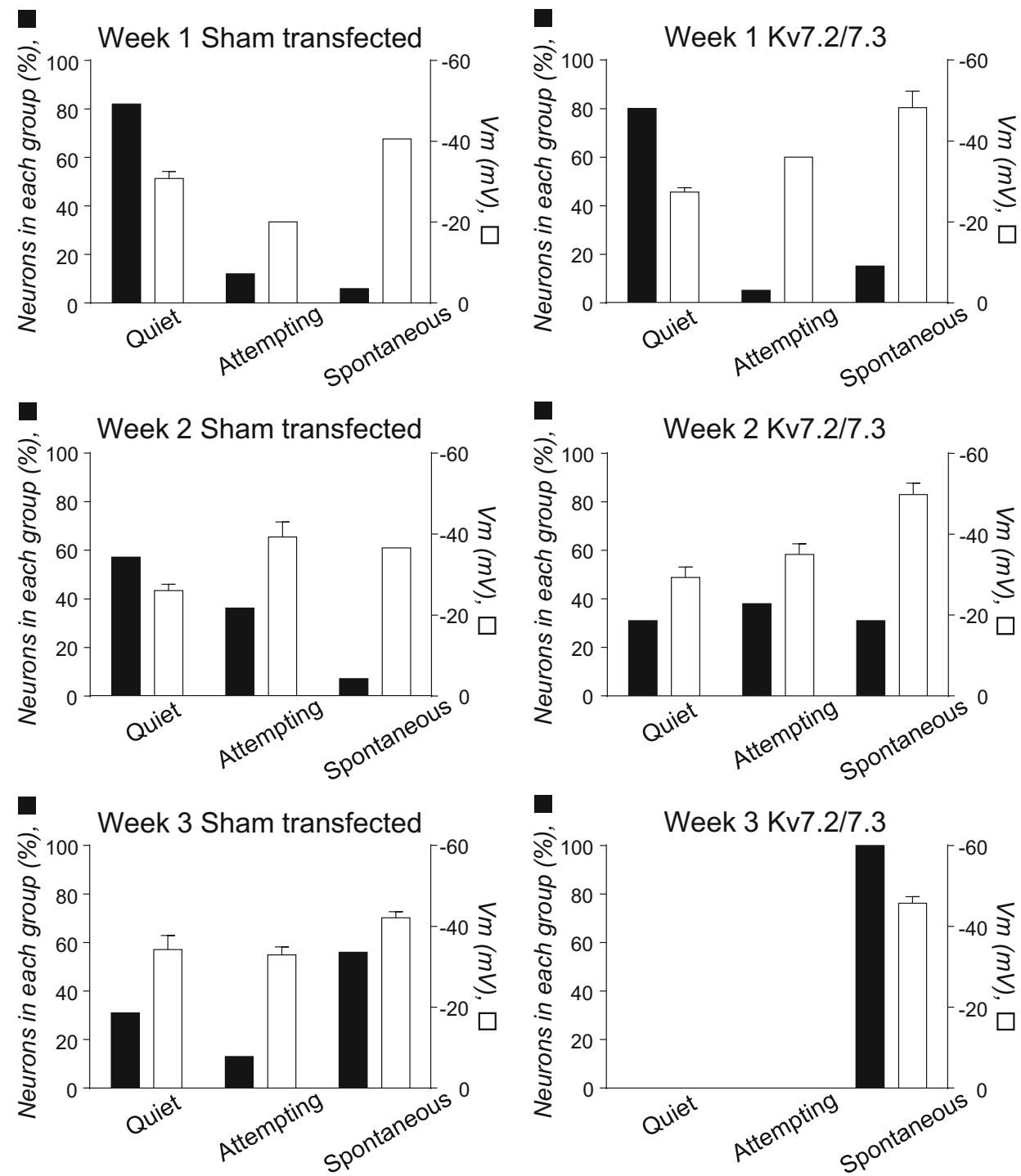
( $n=12 ; p<0.01)$, and Kv7 channel selective blocker XE991 $(10 \mu \mathrm{M})$ re-established the firing to $8.5 \pm 2.5 \mathrm{~Hz}$ ( $n=12$; vs. control $p<0.01$ ) (Fig. 5).

\section{Functional maturation and forced expression of Kv7.2/7.3 channels in hiPSC-derived neurons}

Based on the observations that $K C N Q$ genes became highly and differentially expressed in mouse striatum, human striatum and hiPSC during in vivo and in vitro differentiation, the effects of forced co-expression of the two subunits, Kv7.2 and Kv7.3, known to constitute heteromeric Kv7 channel, were investigated. This was carried out in an attempt to assess whether such an experimental manoeuvre might accelerate and/or synchronise the functional maturation of hiPSCderived neurons in order to provide a rational basis for enhancing current neuronal differentiation protocols. In these experiments, we measured the individual Vm values and ongoing electrical activity. For the latter, we classified hiPSC-derived neurons in the same way we did in the previous study [37] as showing absence of any activity ('Quiet'), only sub-threshold transient depolarizing events ('Attempting' activity) and activity with overshooting action potentials (true 'Spontaneous' activity, Fig. 6a). Sham-transfected, pre-patterned, CTR33Qn1-derived neurons showed rather little spontaneous action potential generation during the first 2 weeks of neuronal differentiation $(6 \%(1 / 17)$ at week 1 and $7 \%(1 / 14)$ at week 2); this had risen to $56 \%(9 / 16)$ by week 3 (Fig. 6b, Table 1). Forced co-expression of Kv7.2/7.3 resulted in a dramatic acceleration of maturation, such that the proportion of spontaneously active neurons was augmented to $17 \%(3 / 18)$ at week 1 , $31 \%(5 / 16)$ at week 2 and, most strikingly, $100 \%(12 / 12)$ at

Table 1 Proportions and percentages of sham-transfected (left) and forced Kv7.2/7.3 co-expressing (+ Kv7.2/7.3, right) CTR33Qn1derived neurons which demonstrated each of the different types of spontaneous action potentials (Quiet, Attempting or Spontaneous) during weeks 1 (upper), 2 (middle) and 3 (lower) of neuronal differentiation postplate down in vitro

\begin{tabular}{|c|c|c|c|c|c|}
\hline \multirow[t]{2}{*}{ Week } & \multirow[t]{2}{*}{ Activity type } & \multicolumn{2}{|c|}{ Sham transfected } & \multicolumn{2}{|l|}{$+\mathrm{Kv} 7.2 / 7.3$} \\
\hline & & Proportion & $\%$ & Proportion & $\%$ \\
\hline \multirow[t]{3}{*}{1} & Quiet & $14 / 17$ & 82 & $14 / 18$ & 78 \\
\hline & Attempting & $2 / 17$ & 12 & $1 / 18$ & 5 \\
\hline & Spontaneous & $1 / 17$ & 6 & $3 / 18$ & 17 \\
\hline \multirow[t]{3}{*}{2} & Quiet & $8 / 14$ & 57 & $5 / 16$ & 31 \\
\hline & Attempting & $5 / 14$ & 36 & $6 / 16$ & 38 \\
\hline & Spontaneous & $1 / 14$ & 7 & $5 / 16$ & 31 \\
\hline \multirow[t]{3}{*}{3} & Quiet & $5 / 16$ & 31 & $0 / 12$ & 0 \\
\hline & Attempting & $2 / 16$ & 13 & $0 / 12$ & 0 \\
\hline & Spontaneous & $9 / 16$ & 56 & $12 / 12$ & 100 \\
\hline
\end{tabular}

week 3 (Fig. 6b, Table 1). These differences correlated well with resting $\mathrm{Vm}$.

This enhanced functional maturation could have resulted from Kv7-dependent hyperpolarization or from other changes in the resting or excitable membrane properties of the neurons. To test this, we measured the initial resting $\mathrm{Vm}$, then neutralised any difference in potential by imposing a steady hyperpolarization to $-70 \mathrm{mV}$, followed by $100-\mathrm{ms}$ current injection in order to induce action potentials; the effects of dpp and Kv7.2/7.3 forced co-expression were determined statistically using two-way ANOVA. For Vm, there were significant effects of both Kv7.2/7.3 overexpression $(p<0.0001)$ and weeks in vitro $(p<0.01)$. Indeed, by week $3, \mathrm{Vm}$ of the sham-transfected neurons had hyperpolarized to $-38.5 \pm 1.7$ ( $n=16, p<0.05$ ), whilst that of the Kv7.2/7.3 overexpressing neurons had hyperpolarized to $-45.5 \pm 1.7 \mathrm{mV}(n=11, p<$ 0.05 ); this was $7 \mathrm{mV}$ more negative than 3 -week shamtransfected neurons $(p<0.01)$. For Rin, there were significant effects only of Kv7.2/7.3 overexpression $(p<0.02)$, presumably reflecting enhanced $\mathrm{M}$-current development; see further below and Table 2 .

The majority of CTR33Qn1-derived neurons, including those at week 1 , demonstrated robust induced action potentials following an imposed depolarization from $-70 \mathrm{mV}$, with a tendency towards more action potential trains as differentiation proceeded (Table 3). However, there were no significant effects of either weeks in vitro or Kv7.2/7.3 overexpression on any of the induced action potential parameters (threshold, overshoot, peak amplitude, afterhyperpolarization, peak rates of depolarization and repolarization or half-width). Hence, the simplest explanation for the increased spontaneous activity at week 3 and its amplification on overexpressing Kv7.2/7.3 channels is that it results directly from the membrane hyperpolarization, rather than from other changes in resting or excitable properties.

In order to validate these data, experiments were performed in an unrelated hiPCS line, 34D6. After 2 weeks of differentiation, in those pre-patterned 34D6-derived neurons which exhibited spontaneous activity, application of $10 \mu \mathrm{M}$ of the Kv7 channel opener, retigabine, resulted in reversible hyperpolarizing responses which were significantly larger in the $\mathrm{Kv} 7.2 / 7.3(-7.7 \pm 2.0 \mathrm{mV}, n=3)$ than in the sham group ($5.4 \pm 0.8 \mathrm{mV}, n=3, p<0.03)$ and evoked a concomitantly more pronounced attenuation in neuronal firing rate Fig. 7a, b). At this point of neuronal differentiation, sham-transfected 34D6-derived neurons as a group exhibited a mean Vm of $39.9 \pm 2.2(n=12)$. Less than half $(5 / 12)$ of this population, with a mean membrane potential of $-47.2 \pm 1.9 \mathrm{mV}$, showed full spontaneous action potential activity (Fig. 7c). Of the remainder, $2 / 12(-31.5$ and $-36.4 \mathrm{mV})$ showed some subthreshold ('Attempting') activity, whilst 5/12 (mean Vm $34.9 \pm 2.9 \mathrm{mV}$ ) appeared totally quiet (Fig. 7c). Strikingly, forced co-expression of Kv7.2/7.3 resulted in significant 
Table 2 Analysis of passive and active parameters of induced action potentials from sham-transfected (left) and forced Kv7.2/7.3 co-expressing (right) CTR33Qn1-derived neurons during 1 (upper), 2 (middle) and 3 (lower) weeks of neuronal differentiation post-plate down in vitro

\begin{tabular}{|c|c|c|c|c|c|c|c|c|}
\hline \multirow[t]{2}{*}{ Week } & & \multirow[t]{2}{*}{ Action potential parameters } & \multicolumn{3}{|c|}{ Sham transfected } & \multicolumn{3}{|c|}{$+\mathrm{Kv} 7.2 / 7.3$} \\
\hline & & & Mean & SEM & $n$ & Mean & SEM & $n$ \\
\hline \multirow[t]{10}{*}{1} & \multirow[t]{3}{*}{ Passive } & $\mathrm{Vm}(\mathrm{mV})$ & -30.2 & 1.8 & 17 & -30.9 & 2.0 & 20 \\
\hline & & $\operatorname{Rin}(G \Omega)$ & 1.65 & 0.14 & 16 & 1.12 & 0.11 & 17 \\
\hline & & $\mathrm{Cp}(\mathrm{pF})$ & 14.1 & 2.0 & 13 & 13.7 & 1.4 & 15 \\
\hline & \multirow[t]{7}{*}{ Spike analysis } & Threshold (mV) & -30.6 & 2.4 & 16 & -27.9 & 1.7 & 16 \\
\hline & & Overshoot (mV) & 29.0 & 4.5 & 16 & 25.2 & 4.0 & 16 \\
\hline & & Afterhyperpolarization (mV) & -57.0 & 4.3 & 16 & -54.3 & 2.7 & 16 \\
\hline & & Amplitude (mV) & 86.0 & 6.4 & 16 & 79.5 & 5.2 & 16 \\
\hline & & Depolarization rate $(\mathrm{V} / \mathrm{s})$ & 70.0 & 12.2 & 16 & 62.3 & 9.9 & 16 \\
\hline & & Repolarization rate (V/s) & -49.6 & 9.5 & 16 & -38.6 & 6.7 & 16 \\
\hline & & Half-width (ms) & 2.9 & 0.4 & 16 & 3.1 & 0.3 & 16 \\
\hline \multirow[t]{10}{*}{2} & \multirow[t]{3}{*}{ Passive } & $\mathrm{Vm}(\mathrm{mV})$ & -31.4 & 2.3 & 14 & -37.8 & 2.6 & 16 \\
\hline & & $\operatorname{Rin}(G \Omega)$ & 1.36 & 0.19 & 12 & 0.88 & 0.12 & 11 \\
\hline & & $\mathrm{Cp}(\mathrm{pF})$ & 10.9 & 2.8 & 8 & 17.5 & 4.2 & 9 \\
\hline & \multirow[t]{7}{*}{ Spike analysis } & Threshold (mV) & -38.0 & 3.0 & 12 & -30.9 & 3.2 & 11 \\
\hline & & Overshoot (mV) & 33.2 & 6.9 & 12 & 37.4 & 6.9 & 11 \\
\hline & & Afterhyperpolarization (mV) & -64.3 & 5.7 & 12 & -56.1 & 2.4 & 11 \\
\hline & & Amplitude (mV) & 97.5 & 11.6 & 12 & 93.5 & 6.7 & 11 \\
\hline & & Depolarization rate (V/s) & 83.0 & 14.0 & 12 & 94.2 & 18.4 & 11 \\
\hline & & Repolarization rate (V/s) & -56.2 & 12.6 & 12 & -45.8 & 8.8 & 11 \\
\hline & & Half-width (ms) & 3.0 & 0.5 & 12 & 2.8 & 0.3 & 11 \\
\hline \multirow[t]{10}{*}{3} & \multirow[t]{3}{*}{ Passive } & $\mathrm{Vm}(\mathrm{mV})$ & $-38.5 * *$ & 1.7 & 16 & $-45.5^{* *}$ & 1.7 & 11 \\
\hline & & $\operatorname{Rin}(G \Omega)$ & 0.79 & 0.06 & 12 & 0.61 & 0.05 & 10 \\
\hline & & $\mathrm{Cp}(\mathrm{pF})$ & 17.1 & 2.8 & 11 & 16.3 & 2.5 & 10 \\
\hline & \multirow[t]{7}{*}{ Spike analysis } & Threshold (mV) & -33.0 & 2.5 & 12 & -32.4 & 3.9 & 10 \\
\hline & & Overshoot (mV) & 34.19 & 5.1 & 12 & 42.2 & 3.8 & 10 \\
\hline & & Afterhyperpolarization (mV) & -56.0 & 5.2 & 12 & -60.7 & 2.9 & 10 \\
\hline & & Amplitude (mV) & 90.2 & 7.8 & 12 & 102.9 & 3.3 & 10 \\
\hline & & Depolarization rate $(\mathrm{V} / \mathrm{s})$ & 84.8 & 10.5 & 12 & 104.7 & 10.0 & 10 \\
\hline & & Repolarization rate $(\mathrm{V} / \mathrm{s})$ & -40.9 & 5.0 & 12 & -49.4 & 6.4 & 10 \\
\hline & & Half-width (ms) & 3.0 & 0.6 & 12 & 2.9 & 0.6 & 10 \\
\hline
\end{tabular}

$V m$ membrane potential, Rin input resistance, $C p$ whole-cell capacitance

**Significantly different from each other at $p<0.01$

hyperpolarization to a mean $\mathrm{Vm}$ of $-51.3 \pm 1.1 \mathrm{mV}(n=11, p$ $<0.001$ ), and now all of the cells showed full spontaneous action potential activity (Fig. 7b, c). To underscore the importance of a hyperpolarised $\mathrm{Vm}$ to the functional maturation of the neuronal network and gain further insight into its mechanism of generation, activity was measured during artificial hyperpolarisation by current injection. In those shamtransfected neurons which did not exhibit spontaneous activity ('Quiet'), hyperpolarization of their Vm to $-70 \mathrm{mV}$ resulted in all neurons (11/11 neurons) firing repetitively, as exemplified in Fig. 7d. Thus, these neurons clearly had the potential to generate spontaneous activity yet lacked the mechanism required to bring $\mathrm{Vm}$ to a level sufficiently hyperpolarized to remove $\mathrm{Na}^{+}$channel inactivation; one such mechanism could well be the regulated expression of Kv7 channels.

To address this point further, we recorded the $\mathrm{Na}^{+}$ currents during voltage-clamp in samples of shamtransfected and Kv7.2/7.3 overexpressing CTR33Qn1derived neurons at weeks 1, 2 and 3 in culture (Fig. 8a). By two-way ANOVA, there were no significant effects of weeks in vitro or Kv7.2/7.3 overexpression (Fig. 8b). However, the progressive hyperpolarization, which occurred during differentiation, and which was enhanced by over co-expression of the Kv7.2/7.3 channels, brought resting $\mathrm{Vm}$ values within the range of overlap between the $\mathrm{Na}^{+}$activation and inactivation curves 
Table 3 Proportion (\%) of shamtransfected (left) and forced Kv7.2/7.3 co-expressing (right) CTR33Qn1-derived neurons which demonstrated each of the different types of induced action potentials during weeks 1 (upper), 2 (middle) and 3 (lower) weeks of neuronal differentiation post-plate down in vitro

\begin{tabular}{|c|c|c|c|c|c|}
\hline \multirow[t]{2}{*}{ Week } & \multirow[t]{2}{*}{ Induced action potential type } & \multicolumn{2}{|c|}{ Sham transfected } & \multicolumn{2}{|l|}{$+\mathrm{Kv} 7.2 / 7.3$} \\
\hline & & Proportion & $\%$ & Proportion & $\%$ \\
\hline \multirow[t]{5}{*}{1} & None & $1 / 17$ & 6 & $0 / 16$ & 0 \\
\hline & Attempting single & $0 / 17$ & 0 & $0 / 16$ & 0 \\
\hline & Single & $5 / 17$ & 29 & $4 / 16$ & 25 \\
\hline & Attempting train & $1 / 17$ & 6 & $3 / 16$ & 19 \\
\hline & Train & $10 / 17$ & 59 & $9 / 16$ & 56 \\
\hline \multirow[t]{5}{*}{2} & None & $0 / 12$ & 0 & $0 / 11$ & 0 \\
\hline & Attempting single & $0 / 12$ & 0 & $0 / 11$ & 0 \\
\hline & Single & $3 / 12$ & 25 & $2 / 11$ & 18 \\
\hline & Attempting train & $1 / 12$ & 8 & $2 / 11$ & 18 \\
\hline & Train & $8 / 12$ & 67 & $7 / 11$ & 64 \\
\hline \multirow[t]{5}{*}{3} & None & $0 / 12$ & 0 & $0 / 11$ & 0 \\
\hline & Attempting single & $0 / 12$ & 0 & $0 / 11$ & 0 \\
\hline & Single & $3 / 12$ & 25 & $0 / 11$ & 0 \\
\hline & Attempting train & $0 / 12$ & 0 & $0 / 11$ & 0 \\
\hline & Train & $9 / 12$ & 75 & $0 / 11$ & 100 \\
\hline
\end{tabular}

None $=$ no significant voltage excursions from baseline; Attempting single $=$ voltage excursions which do not overshoot $0 \mathrm{mV}$; Single $=$ one excursion only, but which overshoots $0 \mathrm{mV}$; Attempting train $=$ several excursions, but only one which overshoots $0 \mathrm{mV}$; Train = several excursions, with more than one which overshoots $0 \mathrm{mV}$
(Fig. 8c-h), thus removing enough of the steady-state inactivation to facilitate action potential generation.

\section{Discussion}

The role of ion channels in neurogenesis and stem cell development has been quite extensively studied. Evidence has been provided for a role of $\mathrm{Ca}_{\mathrm{V}} 3.1$ voltage-gated L-type $\mathrm{Ca}^{2+}$ channels in the differentiation of neural stem/progenitor cells [9] and of $\mathrm{Kv} 3.1 \mathrm{~K}^{+}$channels in the proliferation and neuronal differentiation of adult neural precursor cells [43]. Expression of Kv7.4 channels was recently reported in neurons derived from embryonic stem cells [28], and a potential role of Kv7.2/ 7.3 channels in differentiation, synaptogenesis and synaptic function of mouse hippocampal and embryonic stem cellderived neurons has been indicated [44].

In the present study, we explored the role of Kv7 (Kv7.2/ 7.3) channels in the development and neuronal differentiation in mouse striatum and in the functional maturation of hiPSCderived neurons. In the striatal neurons, we found a close correlation between the hyperpolarization of $\mathrm{Vm}$, the expression of Kv7 channel subunit proteins both in vivo, between embryonic stages E13 and E17, and subsequently when cultured in vitro. Crucially, expression of mRNA encoding Kv7 subunits in the human developing striatum demonstrated a very similar ontogeny. Likewise, in the hiPSC-derived neurons, we observed a comparable relation between Kv7 channel expression and the development of normal excitable activity. In this latter case, at least, this relationship is likely to have been causal because the development of excitability was enhanced by overexpression of the $\mathrm{Kv} 7.2 / \mathrm{Kv} 7.3$ heteromeric channels.

In addition to the increased overall $\mathrm{Kv} 7$ channel expression, another factor which might favour the increasing influence of the Kv7 channels in the maturation of the mouse MSNs could be the progressive switch from homomeric $\mathrm{Kv} 7.2$ to heteromeric Kv7.2/7.3 channels as suggested by the qPCR experiments. Since the heteromer has a higher affinity for the membrane phospholipid phosphatidylinositol4,5-bisphosphate $\left(\mathrm{PIP}_{2}\right)$ [21, 36], which is required for Kv7 channel opening, this itself might lead to a progressively larger current and increased membrane potential during development. In the hiPSC-derived neurons, the switch may be towards more Kv7.5 (KCNQ5), a subunit highly enriched in the adult striatum and which is a robust marker for human MSNs, as described in the Allen Human Brain Atlas (http://human. brain-map.org.).

The Kv7-driven membrane hyperpolarization would itself favour the expression of excitable properties, as indicated by the increased spontaneous activity of the developing hiPSCderived neurons during a brief imposed hyperpolarization. Mechanistically, the key effect of developmental or imposed upregulation of the Kv7 channels was to bring the resting membrane potential within the optimal range for $\mathrm{Na}^{+}$channel activation where activation and inactivation parameters overlap (and hence favour spontaneous action potential firing), without any change in the amplitude or kinetic parameters of 
Fig. 7 Forced expression of Kv7.2/7.3 channels facilitates functional maturation of 34D6 hiPSC-derived neurons. a Pharmacological identification of Kv7.2/7.3 channels (retigabineactivated) in an exemplar (injected current $=0 \mathrm{pA}$ ), shamtransfected, spontaneously active 34D6 hiPSC-derived neuron following 2 weeks of in vitro neuronal differentiation. Vm was measured in current-clamp mode of the whole-cell patch-clamp configuration in the absence and presence of $10 \mu \mathrm{M}$ retigabine (indicated above the main trace by a transparent box). Below the trace are extracted action potential events shown on a fester time base. b Pharmacological identification of $\mathrm{Kv} 7.2 / 7.3$ channels (retigabine-activated) in an exemplar (injected current $=$ $0 \mathrm{pA}), \mathrm{Kv} 7.2 / 7.3$ co-transfected, spontaneously active 34D6 hiPSC-derived neuron following 2 weeks of in vitro neuronal differentiation. Recording and display parameters as in a. $\mathbf{c}$ Bar graphs showing percentage of 34D6 hiPSC-derived neurons exhibiting no activity (Quiet), attempting activity (Attempting) or spontaneous activity (Spontaneous) (black bars, left $y$ axis) and their mean $\mathrm{Vm}$ (open bars, right $y$-axis) in shamtransfected (left panel) and Kv7.2/ 7.3 co-transfected 34D6 hiPSCderived neurons (right panel) following 2 weeks of in vitro neuronal differentiation. $\mathbf{d}$ Neuronal activity in an exemplar in untransfected quiet $34 \mathrm{~d} 6$ hiPSC-derived neuron following 2 weeks of differentiation evoked by artificial current injection to bring Vm below $-50 \mathrm{mV}$ (indicated by a black bar above the main trace). Recording and display parameters as in $\mathbf{a}$ a

Sham transfected

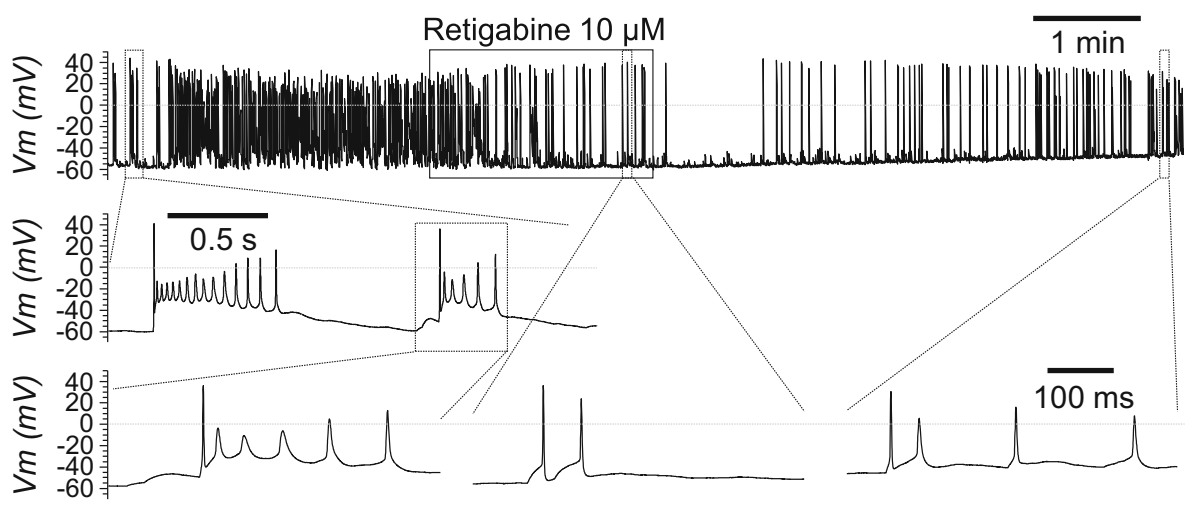

b

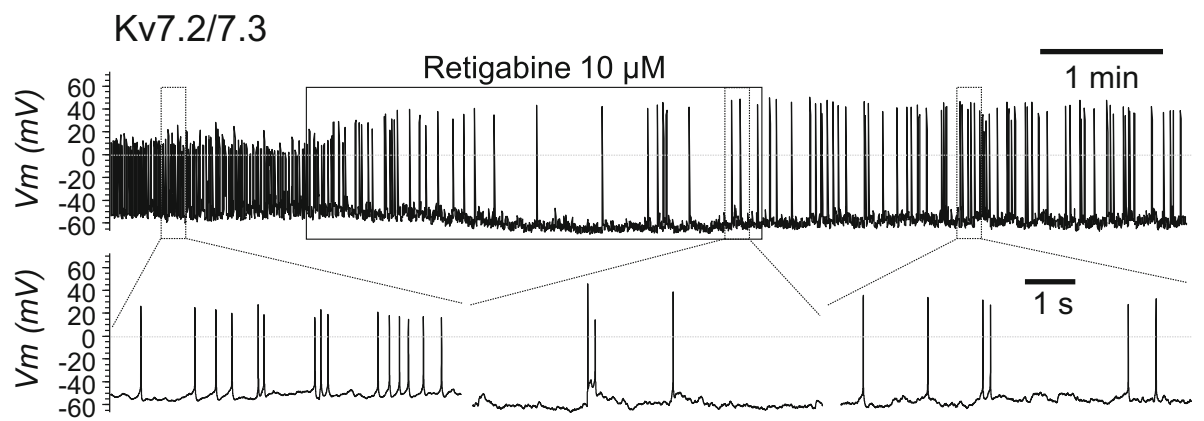

C
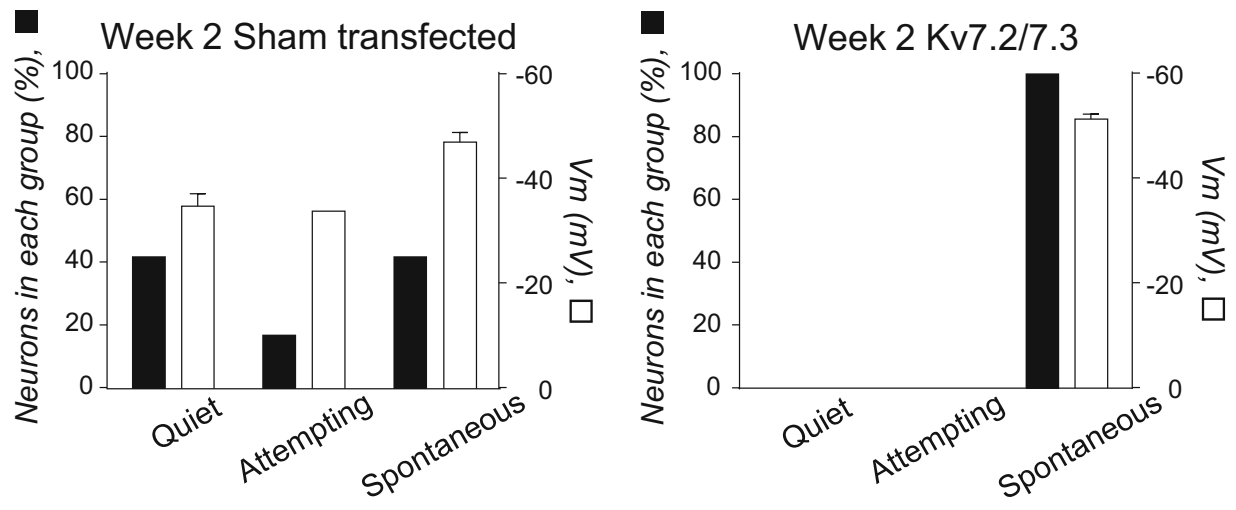

Sham + hyperpolarization

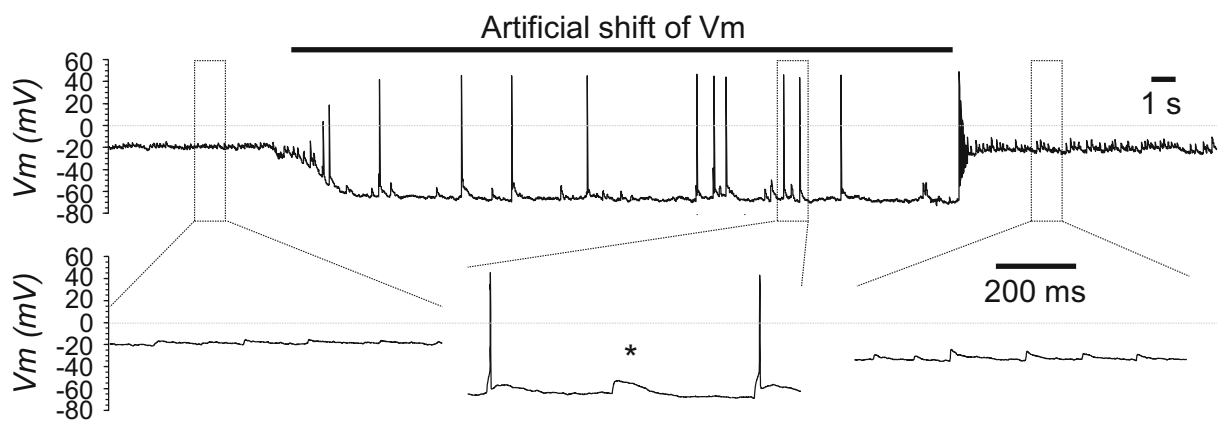

the $\mathrm{Na}^{+}$current or action potential themselves. However, further effects on the developmental process itself might well result from, for example, increased $\mathrm{Ca}^{2+}$ entry through coactivated voltage-gated $\mathrm{Ca}^{2+}$ channels $[9,29]$ or an increased gradient for $\mathrm{Ca}^{2+}$ influx via other mechanisms. Further, $\mathrm{K}^{+}$ channels are known to be involved in the proliferation of non-excitable cells such as $\mathrm{T}$ lymphocytes [10] and a variety of tumour cells [16], through mechanisms that are not yet 
entirely clear; and Kv7.4 channels also appear to regulate skeletal muscle development [17].

The results presented herein show that an adequate expression of $\mathrm{Kv} 7$ channels in striatal and hiPSC-derived neurons is vital for functional maturation, demonstrating their crucial role in the normal development and maturation of striatal neurons and of hiPSC-derived striatal neurons. This knowledge can now be harnessed and applied to any pre-patterned neuronal precursor to synchronise and accelerate neuronal differentiation in order to generate meaningful, disease-relevant
Fig. 8 Effect of forced expression of $\mathrm{Kv} 7.2 / 7.3$ channels on voltage-gated $\mathrm{Na}^{+}$ current activation and inactivation characteristics of CTR33Qn1 hiPSC-derived neurons. a Exemplar family of whole-cell currents (upper) during the activation/inactivation voltage-clamp step protocol (lower). Peak $\mathrm{Na}^{+}$current activation and inactivation levels are shown by the single- and double-headed arrows, respectively. b Mean peak \pm SEM $\mathrm{Na}^{+}$current densities measured from the peak of the inward currents exemplified in a. Data from sham-transfected week 1 $(n=8)$, week $2(n=7)$ and week 3 $(n=9)$ are shown by black bars. Data from Kv7.2/7.3 cotransfection week $1(n=12)$, week $2(n=8)$ and week $3(n=$ 10) are shown by grey bars. $\mathbf{c}-\mathbf{h}$ Mean activation and inactivation curves of whole-cell $\mathrm{Na}^{+}$currents recorded in CTR33Qn1-dervied neurons cultured in vitro for 1 (c, d), 2 (e, f) and 3 weeks $(\mathbf{g}, \mathbf{h})$ following sham transfection (c, e, g, black symbols and lines) or forced co-expression of Kv7.2/ 7.3 (d, f, h, grey symbols and lines). Activation curves are depicted by the squares and inactivation curves are shown by the circles. On each panel, also shown are individual $\mathrm{Vm}$ values (triangles) and mean $\mathrm{Vm}$ values (arrow on abscissa). Voltages of half maximal action $\left(\mathrm{Va}_{50}\right)$ and half maximal inactivation $\left(\mathrm{Vi}_{50}\right)$ are also indicated, along with $h$ factors, mean crossing points (downward arrows) and number of cells recorded for each group (n)
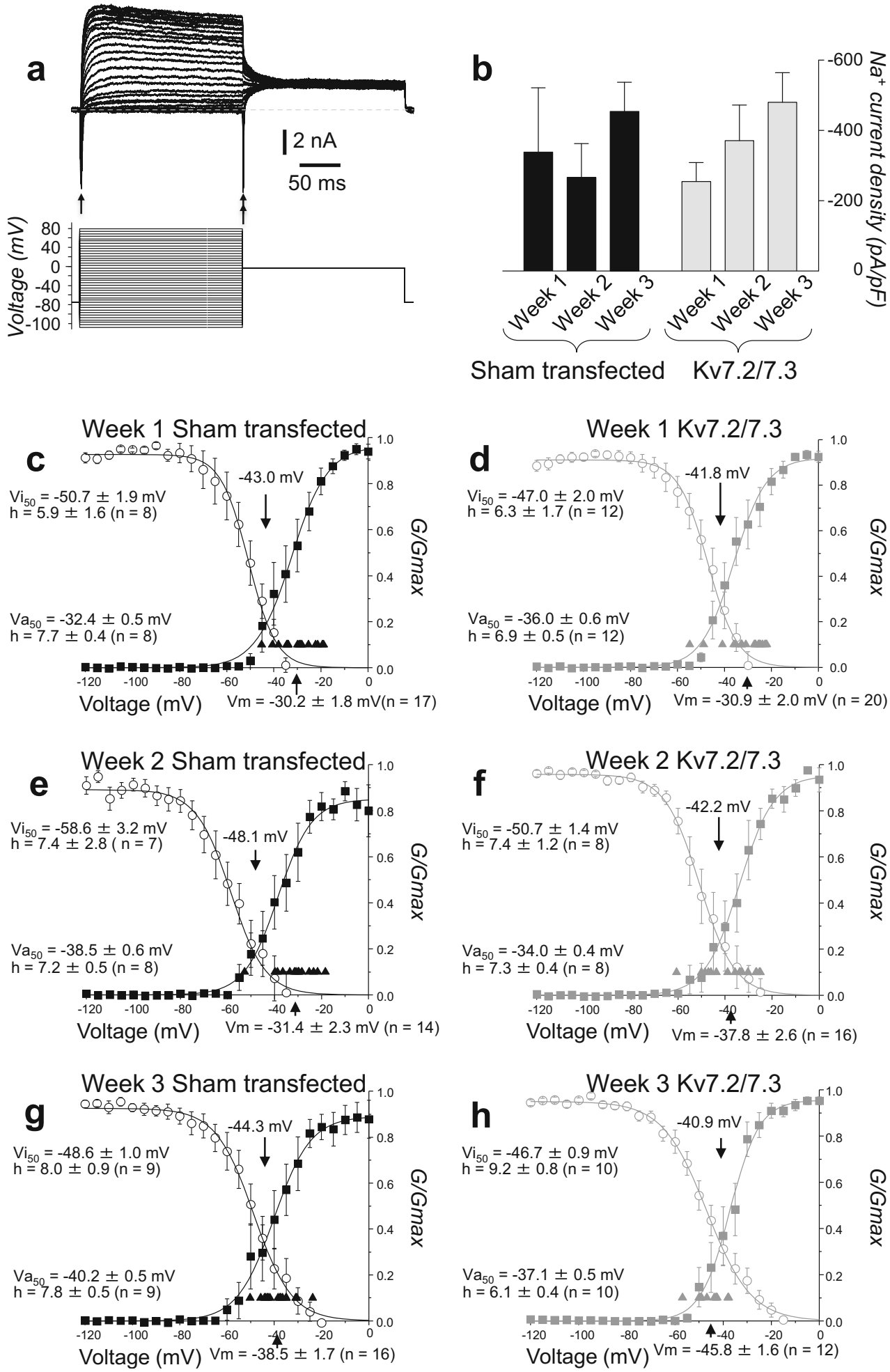
neurons for high-throughput screening and drug discovery for pathologies characterised by neural loss or degeneration.

Acknowledgements The authors would like to thank Dr. Carolina Scherf (Cardiff University Hospital, UK) for the help in obtaining human foetal tissue and Dr. Ellen Gelpi (Neurological Tissue Bank of the BiobankHospital Clinic-IDIBAPS) for human adult tissue.

Authors' contributions VT conducted the patch-clamp electrophysiological experiments. VT and PJK performed the electrophysiological analyses. MS, MP, GG-DB and N-NV performed the striatal dissections for the qPCR studies and analysed those molecular data. PY conducted the immunocytochemistry and its analysis. NDA and VT isolated and cultured the mouse striatal neurons. SY performed all of the hiPSC culture and differentiation studies. VT and SY performed the $K C N Q$ nucleofection protocols. JMH performed multi-electrode arrays and JTB analysed the generated data. VT and PJK originated and co-ordinated the work, with significant collaboration with DAB, NDA, AER, ADR and JMC. The manuscript was written by VT, PJK and NDA and was edited and approved by all authors.

\section{Compliance with ethical standards}

Competing interests The authors declare that they have no competing interests.

Open Access This article is distributed under the terms of the Creative Commons Attribution 4.0 International License (http:// creativecommons.org/licenses/by/4.0/), which permits unrestricted use, distribution, and reproduction in any medium, provided you give appropriate credit to the original author(s) and the source, provide a link to the Creative Commons license, and indicate if changes were made.

\section{References}

1. Bean BP (2007) The action potential in mammalian central neurons. Nat Rev Neurosci 8:451-465

2. Bilican B, Serio A, Barmada SJ, Nishimura AL, Sullivan GJ, Carrasco M, Phatnani HP, Puddifoot CA, Story D, Fletcher J, Park IH, Friedman BA, Daley GQ, Wyllie DJ, Hardingham GE, Wilmut I, Finkbeiner S, Maniatis T, Shaw CE, Chandran S (2012) Mutant induced pluripotent stem cell lines recapitulate aspects of TDP-43 proteinopathies and reveal cell-specific vulnerability. Proc Natl Acad Sci U S A 109:5803-5808

3. Brown DA (1988) M currents. Ion Channels 1:55-94

4. Brown DA, Adams PR (1980) Muscarinic suppression of a novel voltage-sensitive $\mathrm{K}+$ current in a vertebrate neurone. Nature 283: 673-676

5. Brown DA, Passmore GM (2009) Neural KCNQ (Kv7) channels. Br J Pharmacol 156:1185-1195

6. Brown DA, Passmore GM (2010) Some new insights into the molecular mechanisms of pain perception. J Clin Invest 120:13801383

7. Calabresi P, Picconi B, Tozzi A, Ghiglieri V, Di Filippo M (2014) Direct and indirect pathways of basal ganglia: a critical reappraisal. Nat Neurosci 17:1022-1030

8. Cao Y, Bartolome-Martin D, Rotem N, Rozas C, Dellal SS, Chacon MA, Kadriu B, Gulinello M, Khodakhah K, Faber DS (2015) Rescue of homeostatic regulation of striatal excitability and locomotor activity in a mouse model of Huntington's disease. Proc Natl Acad Sci U S A 112:2239-2244
9. D’Ascenzo M, Piacentini R, Casalbore P, Budoni M, Pallini R, Azzena GB, Grassi C (2006) Role of L-type Ca2+ channels in neural stem/progenitor cell differentiation. Eur J Neurosci 23: 935-944

10. DeCoursey TE, Chandy KG, Gupta S, Cahalan MD (1984) Voltage-gated $\mathrm{K}+$ channels in human T lymphocytes: a role in mitogenesis? Nature 307:465-468

11. Delmas P, Brown DA (2005) Pathways modulating neural KCNQ/ M (Kv7) potassium channels. Nat Rev Neurosci 6:850-862

12. Graybiel AM, Aosaki T, Flaherty AW, Kimura M (1994) The basal ganglia and adaptive motor control. Science (New York, NY) 265: 1826-1831

13. Hadley JK, Passmore GM, Tatulian L, Al-Qatari M, Ye F, Wickenden AD, Brown DA (2003) Stoichiometry of expressed KCNQ2/KCNQ3 potassium channels and subunit composition of native ganglionic $M$ channels deduced from block by tetraethylammonium. J Neurosci 23:5012-5019

14. Halliwell JV, Adams PR (1982) Voltage-clamp analysis of muscarinic excitation in hippocampal neurons. Brain Res 250:71-92

15. Hamill OP, Marty A, Neher E, Sakmann B, Sigworth FJ (1981) Improved patch-clamp techniques for high-resolution current recording from cells and cell-free membrane patches. Pflugers Arch 391:85-100

16. Huang X, Jan LY (2014) Targeting potassium channels in cancer. J Cell Biol 206:151-162

17. Iannotti FA, Barrese V, Formisano L, Miceli F, Taglialatela M (2013) Specification of skeletal muscle differentiation by repressor element-1 silencing transcription factor (REST)-regulated Kv7.4 potassium channels. Mol Biol Cell 24:274-284

18. Jentsch TJ (2000) Neuronal KCNQ potassium channels: physiology and role in disease. Nat Rev Neurosci 1:21-30

19. Kelly CM, Precious SV, Torres EM, Harrison AW, Williams D, Scherf C, Weyrauch UM, Lane EL, Allen ND, Penketh R, Amso NN, Kemp PJ, Dunnett SB, Rosser AE (2011) Medical terminations of pregnancy: a viable source of tissue for cell replacement therapy for neurodegenerative disorders. Cell Transplant 20:503513

20. Kemp PJ, Rushton DJ, Yarova PL, Schnell C, Geater C, Hancock JM, Wieland A, Hughes A, Badder L, Cope E, Riccardi D, Randall AD, Brown JT, Allen ND, Telezhkin V (2016) Improving and accelerating the differentiation and functional maturation of human stem cell-derived neurons: role of extracellular calcium and GABA. J Physiol 594:6583-6594

21. Li Y, Gamper N, Hilgemann DW, Shapiro MS (2005) Regulation of Kv7 (KCNQ) K+ channel open probability by phosphatidylinositol 4,5-bisphosphate. J Neurosci 25:9825-9835

22. Livak KJ, Schmittgen TD (2001) Analysis of relative gene expression data using real-time quantitative PCR and the 2(-Delta Delta $\mathrm{C}(\mathrm{T})$ ) method. Methods 25:402-408

23. Marcotti W, Kros CJ (1999) Developmental expression of the potassium current IK,n contributes to maturation of mouse outer hair cells. J Physiol 520(Pt 3):653-660

24. Marrion NV (1997) Control of M-current. Annu Rev Physiol 59: 483-504

25. Mattis VB (2012) The HD-IPSC Consortium. Induced pluripotent stem cells from patients with Huntington's disease show CAGrepeat-expansion-associated phenotypes. Cell Stem Cell 11:264278

26. Nicoleau C, Varela C, Bonnefond C, Maury Y, Bugi A, Aubry L, Viegas P, Bourgois-Rocha F, Peschanski M, Perrier AL (2013) Embryonic stem cells neural differentiation qualifies the role of Wnt/beta-catenin signals in human telencephalic specification and regionalization. Stem Cells 31(9):1763-1774

27. Passmore GM, Selyanko AA, Mistry M, Al-Qatari M, Marsh SJ, Matthews EA, Dickenson AH, Brown TA, Burbidge SA, Main M, 
Brown DA (2003) KCNQ/M currents in sensory neurons: significance for pain therapy. J Neurosci 23:7227-7236

28. Purcell EK, Yang A, Liu L, Velkey JM, Morales MM, Duncan RK (2013) BDNF profoundly and specifically increases KCNQ4 expression in neurons derived from embryonic stem cells. Stem Cell Res 10:29-35

29. Rushton DJ, Mattis VB, Svendsen CN, Allen ND, Kemp PJ (2013) Stimulation of GABA-induced $\mathrm{Ca}^{2+}$ influx enhances maturation of human induced pluripotent stem cell-derived neurons. PLoS One 8: e81031

30. Safiulina VF, Zacchi P, Taglialatela M, Yaari Y, Cherubini E (2008) Low expression of $\mathrm{Kv} 7 / \mathrm{M}$ channels facilitates intrinsic and network bursting in the developing rat hippocampus. J Physiol 586:5437-5453

31. Selyanko AA, Sim JA (1998) Ca2+-inhibited non-inactivating K+ channels in cultured rat hippocampal pyramidal neurones. J Physiol 510(Pt 1):71-91

32. Shah M, Mistry M, Marsh SJ, Brown DA, Delmas P (2002) Molecular correlates of the M-current in cultured rat hippocampal neurons. J Physiol 544:29-37

33. Shen W, Hamilton SE, Nathanson NM, Surmeier DJ (2005) Cholinergic suppression of KCNQ channel currents enhances excitability of striatal medium spiny neurons. J Neurosci 25:7449-7458

34. Shi L, Bian X, Qu Z, Ma Z, Zhou Y, Wang K, Jiang H, Xie J (2013) Peptide hormone ghrelin enhances neuronal excitability by inhibition of Kv7/KCNQ channels. Nat Commun 4:1435

35. Song M, Mohamad O, Chen D, Yu SP (2013) Coordinated development of voltage-gated $\mathrm{Na}+$ and $\mathrm{K}+$ currents regulates functional maturation of forebrain neurons derived from human induced pluripotent stem cells. Stem Cells Dev 22:1551-1563

36. Telezhkin V, Brown DA, Gibb AJ (2012) Distinct subunit contributions to the activation of M-type potassium channels by PI(4, 5)P2. J Gen Physiol 140:41-53
37. Telezhkin V, Schnell C, Yarova P, Yung S, Cope E, Hughes A, Thompson BA, Sanders P, Geater C, Hancock JM, Joy S, Badder L, Connor-Robson N, Comella A, Straccia M, Bombau G, Brown JT, Canals JM, Randall AD, Allen ND, Kemp PJ (2016) Forced cell cycle exit and modulation of GABAA, CREB, and GSK3beta signaling promote functional maturation of induced pluripotent stem cell-derived neurons. Am J Physiol Cell Physiol 310:C520-C541

38. Tinel N, Lauritzen I, Chouabe C, Lazdunski M, Borsotto M (1998) The KCNQ2 potassium channel: splice variants, functional and developmental expression. Brain localization and comparison with KCNQ3. FEBS Lett 438:171-176

39. Vonsattel JP, Myers RH, Stevens TJ, Ferrante RJ, Bird ED, Richardson EP Jr (1985) Neuropathological classification of Huntington's disease. J Neuropathol Exp Neurol 44:559-577

40. Wang HS, Pan Z, Shi W, Brown BS, Wymore RS, Cohen IS, Dixon JE, McKinnon D (1998) KCNQ2 and KCNQ3 potassium channel subunits: molecular correlates of the M-channel. Science (New York, NY) 282:1890-1893

41. Weber YG, Geiger J, Kampchen K, Landwehrmeyer B, Sommer C, Lerche H (2006) Immunohistochemical analysis of KCNQ2 potassium channels in adult and developing mouse brain. Brain Res 1077:1-6

42. Wickenden AD, Yu W, Zou A, Jegla T, Wagoner PK (2000) Retigabine, a novel anti-convulsant, enhances activation of KCNQ2/Q3 potassium channels. Mol Pharmacol 58:591-600

43. Yasuda T, Cuny H, Adams DJ (2013) Kv3.1 channels stimulate adult neural precursor cell proliferation and neuronal differentiation. J Physiol 591:2579-2591

44. Zhou X, Song M, Chen D, Wei L, Yu SP (2011) Potential role of $\mathrm{KCNQ} / \mathrm{M}$-channels in regulating neuronal differentiation in mouse hippocampal and embryonic stem cell-derived neuronal cultures. Exp Neurol 229:471-483 